\title{
The construction of national identities
}

\author{
Milena Almagro \\ Department of Economics, New York University \\ DAVID ANDRÉS-CEREZO \\ Department of Economics, European University Institute
}

\begin{abstract}
This paper explores the dynamics of nation-building policies and the conditions under which a state can promote a shared national identity on its territory. A forward-looking central government that internalizes identity dynamics shapes them by choosing the level of state centralization. Homogenization attempts are constrained by political unrest, electoral competition and the intergenerational transmission of identities within the family. We find nation-building efforts are generally characterized by fast interventions. We show that a zero-sum conflict over resources pushes long-run dynamics toward homogeneous steady states and extreme levels of (de)centralization. We also find the ability to foster a common identity is highly dependent on initial conditions, and that country-specific historical factors can have a lasting impact on the long-run distribution of identities.

KeYwords. Cultural evolution, nation-building, national identity, cultural leader, optimal control, political economy, decentralization.
\end{abstract}

JEL Classification. B52, D71, D72, D74, H41, H77, P48, Z10, Z13.

\section{InTRODUCTION}

During the past two centuries, nation-states have arisen in which the vast majority of the population shares a sense of collective belonging, represented by distinctive traditions, culture, language, and sometimes religion. By contrast, we have also observed cases of failed nation-building, in which governments were unable to create a unified national culture. Simultaneously observing such opposite outcomes naturally raises two questions: Which conditions lead to the promotion of a national identity? How do governments achieve this goal? ${ }^{1}$

Milena Almagro: m . almagro@nyu . edu

David Andrés-Cerezo: david . andres@eui . eu

We are grateful to the two anonymous referees for very helpful comments and suggestions. We also want to thank Jess Benhabib, Alberto Bisin, Juan Dolado, Tomás Domínguez-Iino, Guillaume R. Fréchette, Andrea Galeotti, Philipp Kircher, David Levine, Alessandro Lizzeri, David Martínez, Ana Moreno, Paula Onuchic, Jacopo Perego, Matheus Silva, Ennio Stacchetti, and Thierry Verdier, as well as seminar participants at CEMFI, ASREC at Lund University, ASSET at Athens University, the Spanish Economic Association, New York University, and European University Institute. We are indebted to the MacCracken fellowship at New York University and the Salvador de Madariaga EUI program for financial support as we wrote this paper.

${ }^{1}$ The analysis in this paper is only positive and, therefore, we do not make any normative statement about the legitimacy of nation-building attempts or the desirability of having a unified national culture. 
Providing answers to these questions is interesting for several reasons. First, many authors have identified a shared identity as a fundamental prerequisite to economic growth. The reason is that societies polarized along identity cleavages are prone to civil conflict and corruption, all of which are factors generally associated with poor economic performance (e.g., Besley and Reynal-Querol (2014)). ${ }^{2}$ Second, the absence of a common national identity is a source of political instability, as is the case of countries characterized by a center-periphery tension such as Catalan and Basque regions in Spain, Scotland in the UK, Québec in Canada, Flanders in Belgium, Biafra in Nigeria, or Ogaden in Ethiopia. These regions are repeatedly involved in political processes claiming larger political autonomy, the recognition of their cultural distinctiveness, or even the formation of independent nation-states. Moreover, identity differences within a political union may prevent the provision of public goods, hinder redistribution, and lead to suboptimal economic policies (e.g., Guiso et al. (2016)), because they reduce social capital and increase the costs of collective action. Third, processes of nation-building are frequently related to political movements of state centralization and decentralization. In some cases, such as France at the end of the 19th century (Weber (1976)), the relatively fast creation of a unitary state was accompanied by the development of a common identity among citizens with different cultural backgrounds and a vague sense of national belonging. In other cases, such as the Soviet Union or Yugoslavia, the lack of state centralization within the political union coincided with the consolidation of opposing territorial identities (e.g., Bakke and Wibbels (2006); Sekulic et al. (1994)). In this regard, some authors suggest European leaders have relied on the expectation that a gradual political integration would promote the convergence of values and identities among the European population (Spolaore (2013)). However, these expectations have not been fulfilled yet (Guiso et al. (2016)), so whether we should expect the development of a European identity in the future remains an open question.

In the paper, we develop a theoretical model of state nation-building in a peripheral region where two identity groups coexist: nationalists and regionalists. The cultural values of nationalists are aligned with those of the rest of the country, while regionalists have a culturally distinctive regional identity. Our framework incorporates two key ideas related to nation-building episodes. First, the ability of the central government to promote the national identity depends on its capacity to centralize the competences of the peripheral region. By having the power to tax and spend the revenues, the government can implement policies aimed at promoting certain cultural values. ${ }^{3}$ In our model, the main mechanism through which these policies operate is by changing the socialization incentives of the families, because parents want to educate their children to make them

These considerations depend on the particular context and on political philosophy issues beyond the scope of this paper. Our aim is solely to understand, albeit with many limitations, why some countries are divided along ethno-territorial identity cleavages while others are not.

${ }^{2}$ This problem is especially severe in Sub-Saharan Africa where, according to the Afrobarometer, around $50 \%$ of the population identifies more with their ethno-linguistic identity than with the national identity.

${ }^{3}$ Nation-building policies include, for instance, the promotion of an official language, the introduction of a "collective memory" in school curricula, military conscription, or the provision of identity public goods such as patriotic celebrations commemorating important national events. 
fit better in the region where they live. Second, centralization and nation-building policies usually come with episodes of political unrest in the form of protests or even civil war. The reason is that communities with a rooted identity feel aggrieved if their cultural and symbolic demands are not satisfied, or if an external government imposes a centralized state that disregards their cultural distinctiveness. Hence, by mobilizing in public demonstrations, protests, and riots, citizens can influence government policies through channels other than legal institutions.

Specifically, individuals in the peripheral region enjoy utility from consuming a public good associated with their identity (or an associated cultural trait, e.g., the regional language). The total amount of public goods is in fixed supply, giving rise to a zero-sum conflict, which allows us to capture cultural decentralization as the share of regionalist public goods. Identities are transmitted over generations through a process of cultural evolution with two channels of socialization: within the family (vertical transmission) and by society at large (horizontal transmission). As in standard models of cultural evolution (e.g., Bisin and Verdier (2001)), parents choose socialization efforts by weighting the benefits of transmitting their own identities against the potential costs for their children. This evolutionary process gives rise to a differential equation for the fraction of the population attached to the national identity, which is a function of the level of decentralization. A forward-looking government in the central region internalizes these dynamics and shapes them by modifying parents' socialization incentives. This government has a particular objective in mind, which for historical reasons is assumed to include the promotion of the national identity. ${ }^{4}$ However, the government is constrained by welfare losses created by political unrest, with protest participation levels increasing as nationbuilding attempts become stronger. Thus, the problem of the government becomes a nonlinear optimal control problem over an infinite time horizon, in which a trade-off exists between its perceived benefits of having a more nationally-identified population and the costs created by political unrest.

In this setting, we begin by analyzing a problem that is linear in the control variable, which allows us to fully characterize the dynamics of nation-building episodes and to derive three key results. First, we find that optimal nation-building policies involve quick and extreme interventions, so that homogenization is achieved in the fastest possible way. ${ }^{5}$ Concretely, optimal control trajectories follow a Most Rapid Approach Path (MRAP) (Spence and Starrett (1975)). Second, the optimal long-run steady states are characterized by cultural homogeneity within the peripheral region. Because identities are mutually exclusive, gains from one group always come at the expense of the other. Therefore, a forward-looking central government forced to solve this dispute will push homogenization to the maximum possible level, so that preferences in the population are aligned and the zero-sum conflict eventually disappears. Hence, in cases

\footnotetext{
${ }^{4}$ The desire to promote a national identity could be motivated by pure ideological reasons, or by instrumental reasons such as processes of industrialization that require a population with a common language or the need of an army willing to defend the nation.

${ }^{5}$ Throughout the text, we frequently refer to some policies or outcomes as optimal. This actually means they are optimal in a mere mathematical sense and from the point of view of a government that pursues its own goals, which may be different from a social welfare criterion.
} 
where promoting the full assimilation to the national identity is extremely costly, the government will grant full decentralization to the peripheral region and allow regional identities to thrive. Finally, the ability of governments to nation-build is highly dependent on the initial distribution of identities. In particular, we prove the existence of a population threshold above which the government promotes the national identity and vice versa. Small differences in economic, social, and political factors change the location of this threshold and may lead to extremely divergent trajectories, highlighting the contingent nature of nation-building processes. In addition, the model presents severe "regime changes": an exogenous shock to the socioeconomic environment can trigger a sudden shift in the policies of the government. Therefore, our model can explain historical episodes in which states facing similar historical contexts followed disparate nation-building policies.

Then we extend the benchmark model in several directions. First, we check how robust our results are to nonlinear specifications of the objective function. The nonconvex dynamics present in this problem prevent us from using standard optimal control techniques and hinder a full analytic characterization of the optimal path. However, we are able to identify general sufficient conditions under which the long-run distribution of identities remains homogeneous. Interestingly, these conditions are satisfied for certain cases in which parental socialization decisions are characterized by cultural substitution, in contrast to most results in the cultural-evolution literature (Bisin and Verider (2011)). Second, we introduce democratic electoral competition for the central government. In particular, we characterize the Markov equilibrium of a differential game between two forward-looking political parties. Those two parties have aligned nation-building motives but compete to win the benefits of being in office. Whenever the regionalist group is sufficiently pivotal, political parties face a trade-off between targeting this group to increase the probability of winning, and cooperating by proposing policy platforms that promote the national identity. Compared to the case of a secure government, we find that, everything else equal, the preservation of regional identities is more likely in democracies, because regional minorities have an additional instrument beyond protests to voice their demands.

The paper is organized as follows. Section 2 reviews the related literature. Section 3 describes the model. Section 4 includes the main theoretical results. Section 5 provides general sufficiency conditions for our homogenization results. Section 6 introduces electoral competition. In Section 7, we discuss the results and we illustrate the predictions of the model with relevant case studies. Section 8 concludes. All proofs are relegated to the Appendix. ${ }^{6}$

\section{Related literature}

The main contribution of the paper is to formalize the conditions under which nationbuilding takes place and to characterize the dynamics of national identities. As argued by Smith (1992), "national identification has become the cultural and political norm,

\footnotetext{
${ }^{6}$ A supplementary online appendix is available in a supplementary file on the journal website, http:// econtheory.org/supp3040/supplement.pdf
} 
transcending other loyalties in scope and power." Yet theoretical work on this topic is scarce. $^{7}$ In the economics literature, Dessí (2008) studies the role of older generations in creating a shared identity by promoting a collective memory that praises the values and the history of the nation. Our work is complementary to hers. Whereas Dessí (2008) models the transmission of identities as a process of strategic communication of information between generations, in our model, identities correspond to different preferences. Moreover, we model its transmission as a cultural evolutionary process resulting from the interaction between vertical, oblique, and horizontal socialization.

Another set of theoretical contributions that explicitly deals with the formation of national identities emphasizes the role of interstate and modern mass warfare in triggering nation-building behavior by states. Alesina et al. (2017) explore how changes in warfare technology incentivized mass armies by conscription, which in turn pushed states to create a sense of national belonging that increased the willingness to fight for the country. ${ }^{8}$ Sambanis et al. (2015), building upon Shayo (2009) and Sambanis and Shayo (2013), argue that rulers who want to nation-build may find it optimal to promote war against an external power, as expectations of victory increase the international status of the country. We complement these works in two key respects. First, we depart from static models by introducing cultural dynamics that reflect more closely the behavior of nation-building policies over time. Dynamics allow us to make general predictions about the process by which national identities are formed. Second, these papers focus on the role of external wars and assume no internal opposition to nation-building policies. By contrast, our model allows for additional possible causes of nation-building and focuses on the domestic sources of political conflict and cultural resistance to these policies.

On the empirical side, some papers study the impact of different nation-building tools, such as language policy (Aspachs-Bracons et al. (2008), Caminal et al. (2018)), school curricula (Cantoni et al. (2017), Fouka (2020)), compulsory schooling (Bandiera et al. (2019)), mass media and propaganda (Voigtländer and Voth (2015), Blouin and Mukand (2019)), public nationalist holidays (Madestam and Yanagizawa-Drott (2012)), and national football teams (Depetris-Chauvin et al. (2018)). We contribute to this literature by developing a theoretical model that explores the long-run consequences of these policies and the political economy aspects that constrain their implementation.

Our paper also relates to a recent strand of the cultural-transmission literature that studies how different socialization agents shape preference formation, and how different modes of socialization compete with each other. Within this literature, our study is closely related to some papers analyzing how different "cultural leaders," such as media or religious leaders, shape cultural evolution (Hauk and Immordino (2014), Prummer and Siedlarek (2017), Carvalho and Koyama (2016)). We contribute to this literature by

\footnotetext{
${ }^{7}$ For an early discussion on nationalism from an economic point of view, see Breton (1964).

${ }^{8}$ In a closely related paper, Alesina and Reich (2015) analyze in a static setting the different incentives to promote a common identity that democracies and dictatorships face. Aghion et al. (2019) provides empirical support for the theory in Alesina et al. (2017), showing that external military threats encourage public investments in education that spur national identifications.
} 
studying the identity socialization role of a key cultural leader that has received little attention in the literature: the nation-state.

We also connect to two strands of the literature that analyze the interplay between electoral competition and identity formation. On the one hand, within the cultural transmission literature, Bisin and Verdier (2000) and Tabellini (2008) study how majority voting maps the distribution of cultural traits into public policies, and how this mapping feeds back into socialization decisions. On the other hand, Shayo (2009) and Gennaioli and Tabellini (2018) analyze how individuals choose the strength of their national identification in the short-run in response to the relative salience of this dimension in the political realm as compared to the class-based dimension of conflict. We contribute to both strands of literature by introducing perfectly forward-looking political parties that purposefully shape individual identifications and fully internalize the impact of their actions on the future political power of different groups. As a result of not being purely opportunistic, they implement equilibrium policies that reflect the long-run goals of parties in addition to voters' policy preferences.

From a methodological point of view, our key contribution is to introduce a perfectly forward-looking socialization agent that solves a zero-sum conflict between cultural groups while internalizing cultural dynamics. Verdier and Zenou (2018) explore a similar idea in the context of the cultural assimilation of religious communities, although their paper includes no conflict between identities, and the leader chooses when to intervene. The presence of a zero-sum conflict makes our results fundamentally different from theirs: Whereas their optimal solution converges to a long-run outcome in which both cultural groups coexist, our optimal steady states are homogeneous. Nevertheless, given the similar framework analyzed in both papers, some technical and conceptual similarities exist. For example, we both find that optimal trajectories with a linear perperiod utility are characterized by an MRAP.

\section{Model}

Consider a continuous time model of a peripheral region of a country populated at time $t$ by a stationary mass 1 of agents. Agents can be of two types: a fraction $q_{t}$ of type $N$ individuals, nationalists, and a fraction $1-q_{t}$ of type $R$ individuals, regionalists. In each period, all individuals receive identical income per capita normalized to 1 . The government collects a fraction $r \in[0,1]$ of this income through taxes. The government uses total tax revenue $r$ to provide identity (local) public goods $g_{t}^{R}=r \delta_{t}$ and $g_{t}^{N}=r(1-$ $\delta_{t}$ ), where $\delta_{t} \in[0,1]$ is the fraction used to provide public good $g_{t}^{R}$.

All individuals consume all of their after-tax income $c_{t}=(1-r)$ deriving utility $f(1-$ $r$ ), where $f$ is continuous, increasing, and concave with $f(0)=0$, and their associated identity public good, deriving utility $g_{t}^{i}$. Hence, total utility is given by $u_{t}^{i}\left(c_{t}, g_{t}^{i}, g_{t}^{j}\right)=$ $f\left(c_{t}\right)+g_{t}^{i}$. Because $c_{t}=1-r, g_{t}^{N}=\left(1-\delta_{t}\right) r$, and $g_{t}^{R}=\delta_{t} r$, indirect utilities are given by

$$
U_{t}^{N}\left(r, \delta_{t}\right)=f(\underbrace{1-r}_{c_{t}})+\underbrace{\left(1-\delta_{t}\right) r}_{g_{t}^{N}} ; \quad U_{t}^{R}\left(r, \delta_{t}\right)=f(\underbrace{1-r}_{c_{t}})+\underbrace{\delta_{t} r}_{g_{t}^{R}} .
$$


In this way, we capture national/regional identities as different preferences over mutually exclusive "identity" or cultural goods, that is, goods that can only be enjoyed by individuals with a particular religion, language, or other cultural trait attached to the identity. Examples are national holidays commemorating a historical date, museums, monuments of past leaders of the nation, a national football team, and so on. ${ }^{9}$ In addition, the fact that the total amount of club public goods has constant total supply $r$ in every period allows us to interpret $\delta_{t}$, the fraction of the regionalist good, as the level of decentralization of this region. ${ }^{10}$

\section{Cultural transmission}

We endogenize preferences by including cultural dynamics following the culturaltransmission literature (Bisin and Verdier (2001)). Assume asexual reproduction where each parent has one child. Children are first exposed to parental (vertical) socialization, which, if unsuccessful, is followed by a random match to an individual from the population, adopting her trait (horizontal socialization). Hence, transition probabilities are given by

$$
\begin{gathered}
P_{t}^{N N}\left(e_{t}^{N}\right)=e_{t}^{N}+\left(1-e_{t}^{N}\right) q_{t}, \quad P_{t}^{N R}\left(e_{t}^{N}\right)=\left(1-e_{t}^{N}\right)\left(1-q_{t}\right), \\
P_{t}^{R R}\left(e_{t}^{R}\right)=e_{t}^{R}+\left(1-e_{t}^{R}\right)\left(1-q_{t}\right), \quad P_{t}^{R N}\left(e_{t}^{R}\right)=\left(1-e_{t}^{R}\right) q_{t},
\end{gathered}
$$

where $P^{i j}$ is the probability that a child of a parent with trait $i$ is socialized to trait $j$, and $e_{t}^{N} \in[0,1]$ and $e_{t}^{R} \in[0,1]$ are parents' education/socialization efforts. Notice that the more present an identity trait is, the more likely agents in the young generation are to adopt it.

Parents take into account how rewarding is to have each identity in society, and based on that they choose how much effort to put in transmitting their own identities. More concretely, let $V^{i j}$ be the utility that a type $i$ parent derives from having a child with trait $j$, and let $C\left(e_{t}^{i}\right)$ be the socialization cost, assumed to be increasing and convex. Then parent $i$ 's socialization problem at time $t$ is

$$
\max _{e_{t}^{i} \in[0,1]} P_{t}^{i i}\left(e_{t}^{i}\right) V_{t}^{i i}+\left(1-P_{t}^{i i}\left(e_{t}^{t}\right)\right) V_{t}^{i j}-C\left(e_{t}^{i}\right) .
$$

Under the assumption that parents' choices display imperfect empathy, socialization utilities are given by $V^{i i}=c_{t}+g_{t}^{i}$ and $V^{i j}=c_{t} .{ }^{11}$ The following lemma characterizes optimal socialization decisions and the corresponding law of motion for identity dynamics:

\footnotetext{
${ }^{9}$ We can also interpret them in a broader sense, as capturing the idea that some individuals within the peripheral region have different priorities and preferences with respect to government spending.

${ }^{10}$ In this view, decentralization corresponds to the degree of cultural recognition and accommodation of a differentiated nation within the boundaries of the state. This must be differentiated from fiscal or political decentralization, that requires the existence of a local government with fiscal and legislative powers. In any case, all these definitions of decentralization are highly correlated, as the provision of regionalist public goods is usually undertaken by regional governments with some political autonomy.

${ }^{11}$ As is standard in the literature, this assumption implies parents evaluate their children's utility using their own utility function.
} 
LeMma 1. Under imperfect empathy and quadratic costs,

$$
C\left(e_{t}\right)=\frac{1}{2} e_{t}^{2}
$$

the optimal socialization efforts are given by

$$
\begin{aligned}
& e_{t}^{N}=\left(1-q_{t}\right) g_{t}^{N}=\left(1-q_{t}\right)\left(1-\delta_{t}\right) r, \\
& e_{t}^{R}=q_{t} g_{t}^{R}=q_{t} \delta_{t} r
\end{aligned}
$$

and the law of motion for cultural transmission becomes

$$
\dot{q}=q_{t}\left(1-q_{t}\right)\left(e_{t}^{N}-e_{t}^{R}\right)=r q_{t}\left(1-q_{t}\right)\left(1-\delta_{t}-q_{t}\right) .
$$

The proof for this lemma is mechanical and can be found in Section S.1 of the Supplementary Appendix. On the one hand, the parents' optimal choice of socialization effort takes into account how much welfare their children derive from holding their own identity, which depends on the provision of its associated public good. On the other hand, because horizontal transmission is a substitute for vertical transmission, parents' effort will decrease in the size of the group holding their identity in the population at large.

Observe that under cultural substitution and constant government intervention over time $\delta_{t}=\delta \in(0,1)$, three steady states exist with a unique stable and interior steady state given by $q^{S S}=1-\delta$. Hence, our model preserves the standard prediction of the culturalevolution literature of a heterogeneous steady state in which both identities coexist. The main difference in our analysis is, precisely, that the government tailors dynamics at its own will by choosing a path for $\delta$ over time. ${ }^{12}$

\section{Government dynamic problem}

We assume the central government has "de jure" power to decide over $\delta_{t}$ and internalizes the cultural-transmission dynamics. The objective of the government is to choose a path $\left\{\delta_{t}\right\}_{t \geq 0}$ that maximizes:

$$
\begin{gathered}
\max _{\delta_{t} \in[0,1] \forall t \geq 0} \int_{0}^{\infty} e^{-\rho t} W\left(\delta_{t}, q_{t} ; \omega\right) d t \\
\text { s.t. } \dot{q}_{t}=r q_{t}\left(1-q_{t}\right)\left(1-\delta_{t}-q_{t}\right) \\
q(0)=q_{0}, q_{t} \in[0,1],
\end{gathered}
$$

\footnotetext{
${ }^{12}$ We have two reasons to think that in the absence of government intervention, long-run heterogeneity will exist. First, taxes may not be collected or no identity public good may be provided, so that $e_{t}^{N}=e_{t}^{R}=0$ and $q_{t}$ remains constant. Second, both identity public goods $g^{N}$ and $g^{R}$ may be provided in a decentralized way by each of the groups. This reasoning could explain why both nation-building attempts and homogeneous nations have appeared recently in history, when nation-states have obtained coercive power and sufficient capacity to tax the people in all regions. The idea that fiscal capacity is a key determinant of the ability to nation-build can be found in Johnson (2015).
} 
where we define the parameter $\omega \in \Omega$ as the vector of all pertinent parameters in the model.

Assume the government has the following flow utility:

$$
\begin{aligned}
W\left(q_{t}, \delta_{t}\right)= & \underbrace{\psi^{N} q_{t}}_{\mathrm{N}}+\underbrace{\psi^{U}\left[\alpha q_{t} U^{N}\left(\delta_{t}\right)+(1-\alpha)\left(1-q_{t}\right) U^{R}\left(\delta_{t}\right)\right]}_{\mathrm{W}} \\
& -\underbrace{\left.\psi^{S}\left[\beta D_{t}^{N}\left(\delta_{t}, q_{t}\right)\right)+(1-\beta) D_{t}^{R}\left(\delta_{t}, q_{t}\right)\right]}_{\mathrm{L}},
\end{aligned}
$$

with three different goals:

$\mathrm{N}$ "Nation-building" motive: $\psi^{N}$ captures factors that change the incentives to nation-build. Assume $\psi^{N} \geq 0$, so the government is biased toward the national identity. ${ }^{13}$

$\mathrm{W}$ "Welfare" motive: $\psi^{U}$ captures how much the government cares about the utilities of individuals. The central government values utilities asymmetrically, so $\alpha \in(0,1)$ represents the government's weight on nationalists' welfare.

L "Law and order" motive: $\psi^{S}$ captures the loss in welfare created by protests $D_{t}^{N}\left(\delta_{t}, q_{t}\right)$ and $D_{t}^{R}\left(\delta_{t}, q_{t}\right) . \beta \in(0,1)$ represents the government's weight on nationalists' protests. For now, assume the participation rates in protests, $D^{R}$ and $D^{N}$, are given by $^{14}$

$$
D_{t}^{N}\left(\delta_{t}, q_{t}\right)=q_{t} \delta_{t} r, \quad D_{t}^{R}\left(\delta_{t}, q_{t}\right)=\left(1-q_{t}\right)\left(1-\delta_{t}\right) r .
$$

Following Passarelli and Tabellini (2017), these participation rates in protests depend on the emotional reward for the individual of defending his group identity, and they are increasing in the distance between the policy implemented and the policy they deem fair. ${ }^{15}$

For simplicity, we normalize $\psi^{U}=\psi^{S}=1$.

The final problem that the government solves is given by

$$
\begin{aligned}
& \max _{\delta_{t} \in[0,1] \forall t \geq 0} \int_{0}^{\infty} e^{-\rho t}\left\{\psi^{N} q_{t}+\alpha q_{t}\left(f(1-r)\left(1-\delta_{t}\right) r\right)+(1-\alpha)\left(1-q_{t}\right)\left(f(1-r)+\delta_{t} r\right)\right. \\
& \left.\quad-r\left(\beta q_{t} \delta_{t}+(1-\beta)\left(1-q_{t}\right)\left(1-\delta_{t}\right)\right)\right\} d t \\
& \text { s.t. } \dot{q}_{t}=r q_{t}\left(1-q_{t}\right)\left(1-\delta_{t}-q_{t}\right) \\
& \quad q(0)=q_{0}, q_{t} \in[0,1] .
\end{aligned}
$$

\footnotetext{
${ }^{13}$ All results carry through if $\psi^{N} \leq 0$.

${ }^{14}$ These participation rates could also be interpreted as the probability that political unrest reaches some threshold of, for example, secessionist attempts. Moreover, the parameter $\beta$ captures how organized protesters are relative to the other group, or the relative capacity of group leaders to mobilize people.

${ }^{15}$ See the Supplementary Appendix S.2 for the microfoundations for the participation rate in protests. For the moment, note that throughout the paper we assume that individuals are entirely selfish with respect to the policy they feel entitled to. However, as discussed in 2.1.3, the results of the paper are robust to situations in which the policy that individuals deem fair takes into account the size of each of the groups.
} 
Problem (1) captures two key trade-offs of the government. First, a static constantsum conflict on how to split the budget between the two types of public goods exists. Second, the government faces an intertemporal trade-off when deciding whether to promote a common identity among a culturally diverse population. To see this dynamic trade-off, consider a situation in which the government only cares about the utility and size of the nationalist group, and only the protests of regionalist individuals create a loss of welfare. In this case, the government internalizes that increasing $\delta_{t}$ today to reduce the level of protests of the regionalist group also reduces $q_{t}$ through the culturaltransmission mechanism, which in turn, will increase demand for more decentralization in the future, adding further pressure to set higher values of $\delta_{t}$ and making nationbuilding more difficult.

\section{Solution TO THE DYNAMiC PROBLEM AND MAIN RESUlTS}

The logistic equation shaping the evolution of the state variable in problem (1) prevents us from using standard optimal control techniques. Concretely, the first-order conditions of the maximum principle are not sufficient to fully characterize the dynamics, because the Hamiltonian is not jointly concave in $\delta$ and $q$. However, it can be shown that the optimal trajectory is characterized as an MRAP, which can be proved following Spence and Starrett (1975).

Proposition 1. The optimal path for problem (1) is an MRAP. That is, the optimal solution approaches as fast as possible a steady state in which per-period welfare is maximized.

The result that the government will approach a steady state where welfare is maximized at each point in time is intuitive: Staying where the highest benefits are delivered is optimal. Moreover, Proposition 1 implies optimal paths do not involve a smooth approach to the steady state.

Theorem 1. For any value of $\omega \in \Omega$ and any initial condition $q_{0} \in(0,1)$, optimal policies set either $\delta=0$ or $\delta=1$ forever with no switch in policies.

Furthermore, no interior steady state exists so optimal paths approach one of the extreme stationary points of the state variable as fast as possible:

$$
\lim _{t \rightarrow \infty} q_{t}^{*}=0 \quad \text { or } \quad \lim _{t \rightarrow \infty} q_{t}^{*}=1,
$$

where $q_{t}^{*}$ is the path of the state variable under the optimal policy $\delta^{*}$.

Two important insights can be derived from the previous Theorem 1. First, the optimal stationary states in our model are culturally homogeneous. Second, the results above also imply optimal homogenization policies should be fast and intense, so any $\delta_{t} \in(0,1)$ is suboptimal, both along the optimal trajectory and in the steady state. The intuition for these results is simple: If at some point increasing $q$ is optimal, further increasing it at the next instant must also be optimal, because fewer people engage in 
political unrest while more people enjoy the benefits of the public good. Eventually, full homogenization is optimal, so protests are minimized and the conflict about how to split the tax revenues fully vanishes. This result is driven by the constant-sum distributive conflict: A larger provision of one public good always comes at the expense of a reduction in the other good. Therefore, intermediate solutions for $\delta_{t}$ are suboptimal because they imply investing in opposing goals: homogenizing toward $N$ while homogenizing toward $R$.

\section{Initial conditions}

So far, we have established that the only steady-state candidates are $q=0$ or $q=1$. The next result characterizes, given initial conditions, which of those is the long-run optimum.

THeORem 2. For any parameter values, a unique $\overline{q_{0}}$ exists such that the government is indifferent between setting $\delta^{*}=0$ or $\delta^{*}=1$ forever. That is, the optimal policy is characterized by threshold $\overline{q_{0}}$ as follows:

$$
\delta^{*}(q)= \begin{cases}1 & \text { if } q \leq \bar{q}_{0}, \\ 0 & \text { if } q \geq \bar{q}_{0} .\end{cases}
$$

Theorem 2 implies that whether nation-building takes place depends on the initial distribution of preferences: When the national identity is held by a sufficient majority, the short-run costs of regionalist protests are relatively low. As a consequence, the government finds optimal to incur such costs for some time to obtain the long-run benefits of having a a population fully homogenized to the national identity. Interestingly, when promoting the national identity is not worthwhile, the central government refrains from preserving a small nationalist group within the peripheral region and allows the regional identity to thrive, giving rise to a multinational state.

Our model sheds light on the initial question of why some distinctive regional identities persist within some countries. One of our predictions is that regional identities persist if the government finds that granting decentralization today is optimal if, for example, the welfare losses caused by regionalist political opposition are significantly large. By doing so, the demand for decentralization increases over time because regionalist parents socialize their kids to the cultural traits attached to the regional identity. By contrast, the group with an attachment to the identity of the central region observes that the policies of the central government do not represent their preferences, and they refrain from transmitting the national identity. Therefore, relatively strong political opposition to nation-building policies at early stages can prevent the development of a national identity. ${ }^{16}$

Proposition 2. The threshold $\overline{q_{0}}$ is decreasing in $\psi^{N}, \alpha$, and $\beta$.

\footnotetext{
${ }^{16}$ An alternative explanation for the survival of peripheral regional identities is a failure of the central government to fully internalize dynamics, either because of pure myopia or because it does not operate over an infinite time horizon.
} 
The proofs for Propositions 2, 3, and 4 are mostly based on algebra and can be found in Section S.3 of the Supplementary Appendix. We can see that a higher $\psi^{N}$ implies that the benefits from increasing the size of the nationalist group are higher. Hence, everything else equal, an increase in $\psi^{N}$ makes the government nation-build for a larger set of initial identity distributions. As expected, the incentives to nation-build change in the same direction when the weight attached to the utility of nationalist individuals $(\alpha)$ increases or when the harm inflicted by political unrest of the nationalist group $(\beta)$ is larger.

The comparative statics of $\bar{q}_{0}$ in $\rho$ and $r$ are significantly more complex. Furthermore, the sign of $\frac{\partial}{\partial \rho} \bar{q}_{0}$ depends on the other parameters of the model. The following proposition holds.

Proposition 3. The comparative statics on $\rho$ can go both ways:

- If $\alpha$ or $\psi^{N}$ are large enough, then

$$
\frac{\partial}{\partial \rho} \bar{q}_{0}>0
$$

- On the contrary, if $\alpha$ and $\psi^{N}$ are small enough, then

$$
\frac{\partial}{\partial \rho} \bar{q}_{0}<0
$$

To understand the previous result, note that the long-run differential returns between setting $\delta=1$ and $\delta=0$ are decreasing in $\psi^{N}$ and $\alpha$, being negative for sufficiently large values of these parameters. Recall that $\bar{q}_{0}$ is the initial point for which the government is indifferent between setting $\delta=1$ or $\delta=0$ forever. Therefore, starting at $\bar{q}_{0}$, for sufficiently high values of $\psi^{N}$ and $\alpha$, the differential returns between $\delta=1$ and $\delta=0$ are necessarily positive in the short-run. In other words, the government has a relatively strong desire to nation-build in the long-run but faces relatively high returns of setting $\delta=1$ in the short-run. Therefore, when this government is more impatient, the short-run returns become more important and, as a consequence, fewer initial distributions of identities exist for which the government finds nation-building profitable $\left(\bar{q}_{0}\right.$ increases). This last result highlights the fact that conditional on being sufficiently interested in nation-building, more stable governments (interpreted as smaller $\rho$ ) are more likely to develop a widespread national culture.

Proposition 4. The comparative statics on $r$ can go both ways and depend on the other parameters of the model:

- For small $\alpha$, and sufficiently large $\psi^{N}$, it follows

$$
\frac{\partial}{\partial r} \bar{q}_{0}<0
$$

- On the other hand, for large $\alpha$, and sufficiently small $\psi^{N}$, it follows

$$
\frac{\partial}{\partial r} \bar{q}_{0}>0
$$


The previous proposition captures the fact that $\rho$ and $r$ play opposite roles in our model: An increase in $r$ makes dynamics in any direction faster, so it is effectively equal to moving any future point closer to the present, or equivalently, putting more weight on the future. Hence, an increase in $r$ can also be seen as a decrease in $\rho$. Finally, a second effect arises from the government per-period utility flow, but for sufficiently large $\psi^{N}$, the first effect dominates the second.

Therefore, everything else equal and conditional on having sufficiently large nationbuilding motives, countries in which the government has a greater ability to tax are more likely to have a shared national identity. The reason is that the government can implement stronger nation-building policies, which changes $q$ faster and makes episodes of political unrest less prolonged.

\section{Noninterior Steady State: A general Result}

In our previous analysis, both the government's per-period utility flow and the law of motion were linear functions in the control $\delta$. This linearity assumption allowed us to characterize our optimal control policy as an MRAP solution. In this section, we first provide a general result that holds for several specifications of the objective function, including nonlinear functional forms. Then we analyze the robustness of all the results of the baseline case when considering a per-period objective function that is quadratic in $\delta$.

The following result gives sufficiency conditions under which no interior steady state exists.

TheоRем 3. Assume $\delta^{*}(q)$ is a solution to the following optimal control problem:

$$
\begin{aligned}
& \max _{\delta_{t} \in \Delta} \int_{0}^{\infty} e^{-\rho t} W\left(q_{t}, \delta_{t}\right) d t \\
& \text { s.t. } \dot{q}_{t}=g\left(\delta_{t}, q_{t}\right) \text { and } q_{0}=q .
\end{aligned}
$$

Denote by $\delta^{S}(q)$ the stationary policy function

$$
\dot{q}=g\left(q, \delta^{S}(q)\right)=0,
$$

and define function

$$
H(q)=W\left(q, \delta^{S}(q)\right) .
$$

If for some interior $\tilde{q}$, we have $\delta^{*}(\tilde{q})=\delta^{S}(\tilde{q}) \in \Delta^{\mathrm{o}}$, such that $\{g(\tilde{q}, \delta) \mid \delta \in[0,1]\}$ is an open neighborhood of 0 , then $\tilde{q}$ is a local maximum of $H(q)$.

The intuition of the previous theorem is simple: If the per-period utility $H(q)$, derived from the policy $\delta^{S}(q)$ that keeps $q$ unchanged $\left(\dot{q}\left(q, \delta^{S}(q)\right)=0\right)$, can be improved in some feasible direction at certain $\tilde{q}$, then staying at $\tilde{q}$ cannot be optimal, because we can construct an alternative path delivering a higher discounted payoff. In other words, $\tilde{q}$ cannot be an interior steady state. 
Corollary 4. If the function $H(q)=W\left(q, \delta^{S}(q)\right)$ has no local maximum over all feasible values of $q$, the optimal path does not have an interior steady state.

The previous results deliver sufficiency conditions for long-run cultural homogeneity. It is easy to check that for our equation describing cultural dynamics, we have that for any $q \in(0,1),\{g(q, \delta) \mid \delta \in[0,1]\}$ is an open neighborhood of 0 and $\delta^{S}(q)=1-q$ is always feasible, that is, the government can always steer dynamics in its desired direction. ${ }^{17}$ Hence, it is enough to check whether the function

$$
H(q)=W(q, 1-q)
$$

has a local maximum in $(0,1)$.

The conditions for Theorem 3 apply to several objective functions of the government. In what follows, we illustrate its strength with two particular cases.

First, in the linear case of the baseline model, we have that

$$
\begin{aligned}
H(q)=W(q, 1-q)= & \psi^{N} q+(\alpha q+(1-\alpha)(1-q)) f(1-r)+r\left(\alpha q^{2}\right. \\
& \left.+(1-\alpha)(1-q)^{2}-q(1-q)\right),
\end{aligned}
$$

which is strictly convex in $q$ because $H^{\prime \prime}(q)=4 r>0$ and, therefore, does not have any local maxima in $q \in(0,1)$. Hence, by Theorem 3 and its corollary, no interior steady state exists under the optimal policy, a result already shown in Theorem 1.

Second, we can also show that there are no interior steady states when protests are given by a convex quadratic cost, that is, when the government solves the following problem: ${ }^{18}$

$$
\begin{aligned}
& \max _{\delta_{t} \in[0,1]} \int_{0}^{\infty} e^{-\rho t}\left(\psi^{N} q+\alpha q_{t}\left(f(1-r)+r\left(1-\delta_{t}\right)\right)+(1-\alpha)\left(1-q_{t}\right)\left(\left(f(1-r)+r \delta_{t}\right)\right.\right. \\
& \left.\quad-r^{2}\left(\beta q_{t} \delta_{t}^{2}+(1-\beta)\left(1-q_{t}\right)\left(1-\delta_{t}\right)^{2}\right)\right) d t
\end{aligned}
$$

s.t. $\dot{q}_{t}=r q_{t}\left(1-q_{t}\right)\left(1-\delta_{t}-q_{t}\right)$.

Proposition 5. If the government solves Problem (2), no interior steady state exists. Therefore, under the optimal policy function,

$$
\lim _{t \rightarrow \infty} q_{t}=0 \quad \text { or } \quad \lim _{t \rightarrow \infty} q_{t}=1 .
$$

As in the linear case, the key result is that central governments will pursue homogenization to the maximum possible, because doing so minimizes long-run political unrest while maximizing the long-run benefits of having an homogeneous population.

\footnotetext{
${ }^{17}$ This condition does not hold in models where socialization efforts are always strictly positive. This would be the case, for instance, if we assume that there are private rewards of having an identity beyond the consumption of the associated public good. Under such conditions, it may not be possible to reach $q=0$ or $q=1$. However, the government still finds it optimal to provide only one type of public good and to achieve the maximum feasible level of homogenization.

${ }^{18}$ See the Supplementary Appendix S.2 for microfoundations of this functional form of protests.
} 


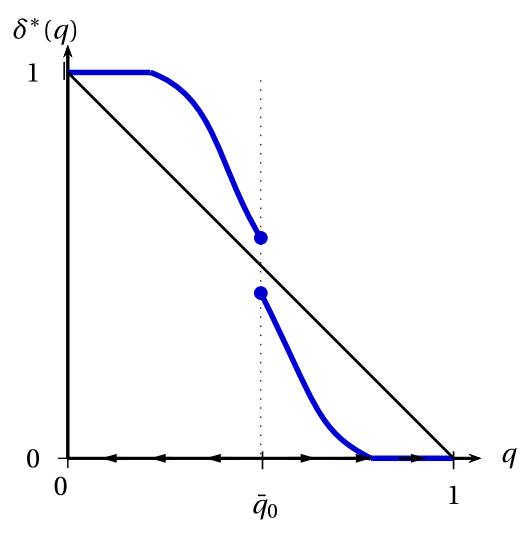

FigURE 1. Optimal policy $\delta^{*}(q)$ with quadratic protests.

This result is robust across different specifications because its main driving force is the zero-sum nature of the conflict, in the sense that the gains for one group always come at the expense of the other. Intuitively, a heterogeneous steady state cannot be optimal, because in the long-run the central government still faces a conflict, which can be eliminated by further homogenizing the population. The previous argument goes through whenever the government faces a strong enough conflict on how to allocate finite resources between different groups. ${ }^{19}$

Finally, we can also prove the optimal policy and long-run dynamics also preserve the threshold property with intervals of fast and extreme interventions for largely homogeneous populations.

Theorem 5. $A \bar{q}_{0} \in(0,1)$ exists such that

$$
\delta^{*}(q)>1-q \quad \text { if } q \leq \bar{q}_{0}, \quad \delta^{*}(q)<1-q \quad \text { if } q \geq \bar{q}_{0} .
$$

Moreover, $\delta^{*}(q)$ is continuous on $\left[0, \bar{q}_{0}\right) \cup\left(\bar{q}_{0}, 1\right]$, and two open neighborhoods of $q=0$ and $q=1$ exist, say, $\mathcal{O}(0)$ and $\mathcal{O}(1)$ in $[0,1]$, such that

$$
\delta^{*}(q)=1 \quad \forall q \in \mathcal{O}(0), \quad \delta^{*}(q)=0 \quad \forall q \in \mathcal{O}(1) .
$$

Figure 1 depicts our qualitative characterization of the optimal policy. Unfortunately, a full analytic characterization of the optimal policy $\delta^{*}(q)$ becomes intractable. However, below we present a numerical example (see Figures 2 and 3). We follow the approach presented in Achdou et al. (2017), which finds the value function using viscosity solutions. Observe that standard methods do not apply in our model, because our value function is not differentiable at the threshold $\bar{q}_{0} \in(0,1)$.

\footnotetext{
${ }^{19}$ Sufficient conditions for the latter are that citizens' valuations of any level of provision of the public good are large enough and participation rates in protests do not explode for low levels of public-good provision.
} 


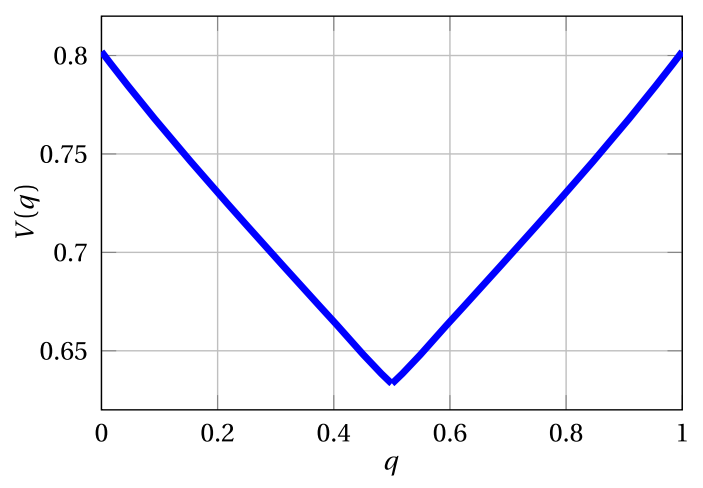

Figure 2. $V(q)$.

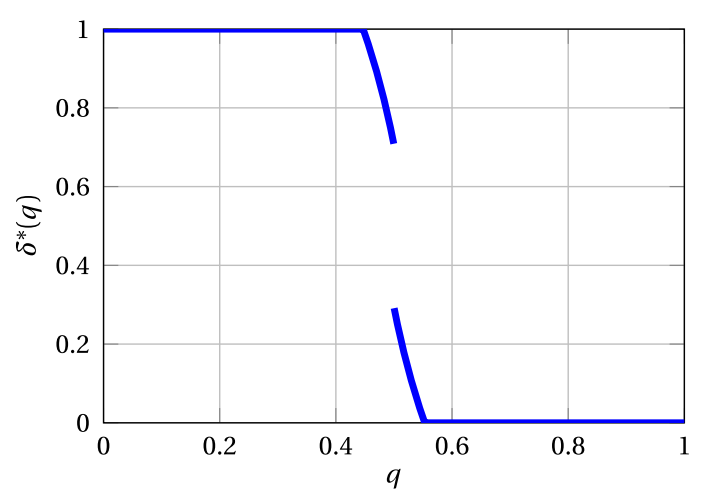

FigURE 3. $\delta^{*}(q)$.

To summarize, the results of extreme homogenization and the existence of an indifference threshold go through beyond the linear specification. Regarding the optimal path for $\delta_{t}$, the numerical results suggest (de)centralization becomes more gradual when protests are convex. To see why, consider the case in which the government starts with a balanced distribution of identities and eventually homogenizes the population toward the national identity. At intermediate values of $q_{t}$, the rate of change $\dot{q}$ is higher and the size of protests bigger than for more homogeneous distributions of identities. Therefore, by setting an interior value for $\delta_{t}$ at early stages, the central government can avoid a large participation in protests of the regionalist group and still move in the desired direction. Interestingly, even with nonlinear specifications, the optimal policy rapidly approaches corner solutions, suggesting the MRAP solution could be a good approximation of optimal nation-building policies. More importantly, although $\delta_{t}$ could take intermediate values along the transition path to the steady state, it eventually reaches a corner solution. Intuitively, an interior long-run value for $\delta_{t}$ cannot be optimal because, due to the identity dynamics, the government will be "investing" in two opposite goals at the same time. 


\section{NATION-BUILDING UNDER ELECTORAL COMPETITION}

In this section, we compare the results of our baseline model of a secure central government with the case in which the central government is democratically elected each period by citizens in the central and peripheral regions. For ease of exposition, we consider the limiting case in which the peripheral region is fully pivotal in national elections, so that only voters of groups $N$ and $R$ determine the result of elections. Nonetheless, in the Supplementary Appendix S.5.4, we explicitly model voters in the central region and we show the results are robust.

We follow the probabilistic voting model with majority voting and aggregate uncertainty proposed by Persson and Tabellini (2000) based on Lindbeck and Weibull (1987). In this model, two parties $A$ and $B$ compete to win elections in every period by making simultaneous policy announcements $\delta^{A}$ and $\delta^{B}$. Political parties commit to implement their announced policies if they happen to be elected. When announcements are $\delta^{A}$ and $\delta^{B}$, party $A$ 's probability of being elected is given by

$$
p^{A}\left(\delta^{A}, \delta^{B}, q\right)=\frac{1}{2}+\frac{(1-q) \phi^{R}-q \phi^{N}}{q \phi^{N}+(1-q) \phi^{R}}\left(\delta^{A}-\delta^{B}\right)=\frac{1}{2}+\Phi(q)\left(\delta^{A}-\delta^{B}\right) .
$$

In the Supplementary Appendix S.5.1, we provide an explicit microfoundation of $p^{i}\left(\delta^{i}, \delta^{-i}, q\right)$. For the moment, note that $\phi^{i}$ captures the intensity of preferences toward policy $\delta$ of group $i .{ }^{20}$ By definition, the probability of winning the election for party $B$ is $p^{B}=1-p^{A}$.

We assume political parties are forward-looking, maximize a discounted stream of utility payoffs, and internalize the dynamics of identities. They have an intrinsic nationbuilding motive, $\psi^{N} q$, with $\psi^{N} \geq 0$ equal for both parties, as well as office motivations, receiving per-period utility equal to $p^{i}$ if they win the elections. ${ }^{21}$ Hence, when the proportion of nationalist is given by $q$, for given announcements $\delta^{i}$ and $\delta^{-i}$, the per-period utility for party $i$ is ${ }^{22}$

$$
W^{i}\left(q, \delta^{i}, \delta^{-i}\right)=\psi^{N} q+p^{i}\left(\delta^{i}, \delta^{-i}, q\right) .
$$

We restrict our attention to Markov perfect equilibria, where strategies only depend on the current state $q$. The problem of player $i$ is to choose a policy announcement $\delta^{i}$ taking the strategy of the other player, $\delta^{-i}$, as given. Equilibrium strategies are characterized by

$$
\delta^{* i}=\arg \max _{\delta \in[0,1]^{[0,1]}}\left\{\mathbb{E}_{0} \int_{0}^{\infty} e^{-\rho t} W^{i}\left(q_{t}, \delta\left(q_{t}\right), \delta^{*-i}\left(q_{t}\right)\right) d t\right\}
$$

\footnotetext{
${ }^{20} \phi^{i}$ is a measure of how much individuals within a group are concerned with the cultural policy/territorial cleavage of policy, relative to other policy dimensions or to intrinsic preferences toward political parties.

${ }^{21}$ The results hold when the strength of nation-building motives is different for both parties, as long as both have strictly positive nation-building motives.

${ }^{22}$ Compared to the benchmark case, we have assumed $\psi^{U}=\psi^{S}=0$. This choice of specification is made for tractability purposes. However, if political parties have "welfare" and "law and order motives," as in the case of the secure government, similar results go through. In the benchmark model, the benefits of holding office for the secure government enter as a constant (which we omitted) and, therefore, they do not alter the results of that section.
} 


$$
\delta^{*-i}=\arg \max _{\delta \in[0,1]^{[0,1]}}\left\{\mathbb{E}_{0} \int_{0}^{\infty} e^{-\rho t} W^{-i}\left(q_{t}, \delta^{* i}\left(q_{t}\right), \delta\left(q_{t}\right)\right) d t\right\},
$$

where $\mathbb{E}_{0}$ is the expectation conditional on $q_{0}$. Parental socialization decisions each period are made after elections have taken place and depend on the implemented policy. Hence, from the point of view of political parties, the value of $\dot{q}$ is a random variable whose realization depends on the policy implemented by the winning party (as the result of elections is also a random variable). Hence, problems (3) and (4) are subject to the following dynamics:

$$
\dot{q}_{t}=g\left(q_{t}, \delta^{i}, \delta^{-i}\right)= \begin{cases}q_{t}\left(1-q_{t}\right)\left(1-\delta^{i}\left(q_{t}\right)-q_{t}\right) & \text { with prob. } p^{i}\left(\delta^{i}\left(q_{t}\right), \delta^{-i}\left(q_{t}\right), q_{t}\right), \\ q_{t}\left(1-q_{t}\right)\left(1-\delta^{-i}\left(q_{t}\right)-q_{t}\right) & \text { with prob. } 1-p_{t}^{i}\left(\delta^{i}\left(q_{t}\right), \delta^{-i}\left(q_{t}\right), q_{t}\right) .\end{cases}
$$

Note that for low values of $q_{t}$, electoral and nation-building motives are not aligned. Therefore, taking what the other party does as given, party $i$ faces a trade-off between increasing the probability of winning elections by announcing a policy that favors the regionalist group $R$, or announcing a less popular policy today that increases $q$ in the future. In this last case, party $i$ faces the cost of reducing the expected benefits from office as well as the probability that this nation-building policy is implemented.

Given that two parties solve identical problems, we restrict our attention to symmetric equilibria. ${ }^{23}$ The solution of the electoral-competition game with nation-building motives is characterized by the following theorem.

Theorem 6. A unique equilibrium in symmetric strategies of the dynamic electoralcompetition game with nation-building motives exists. The equilibrium strategies are described as a threshold policy given by $\tilde{q}_{D}$ such that

$$
\delta^{A *}(q)=\delta^{B *}(q)= \begin{cases}1 & \text { if } q \leq \tilde{q}_{D} \\ 0 & \text { if } q>\tilde{q}_{D}\end{cases}
$$

with $0<\tilde{q}_{D}<\tilde{q}_{S}$, where $\tilde{q}_{S}$ defines the threshold of the symmetric equilibrium for the static electoral competition game, and is given by

$$
\tilde{q}_{S}=\frac{\phi^{R}}{\phi^{N}+\phi^{R}}
$$

As in previous cases, depending on the initial value of $q$, the system converges to one of the two homogeneous steady states. The intrinsic cultural-substitution properties of parental socialization are counteracted by the fact that it is better to be part of the most powerful group. Even if, ceteris paribus, parents exert more socialization effort when their group becomes smaller, the voting system favors individuals who belong to the majority, creating incentives for parents to socialize their kids to the predominant identity.

\footnotetext{
${ }^{23} \mathrm{An}$ interesting extension that merits a paper on its own would be to analyze the dynamic electoral game between forward-looking parties with opposite nation-building motives. In the Supplementary Appendix S.5.3, we discuss this possibility as well as the case of shortsighted but ideologically motivated parties.
} 


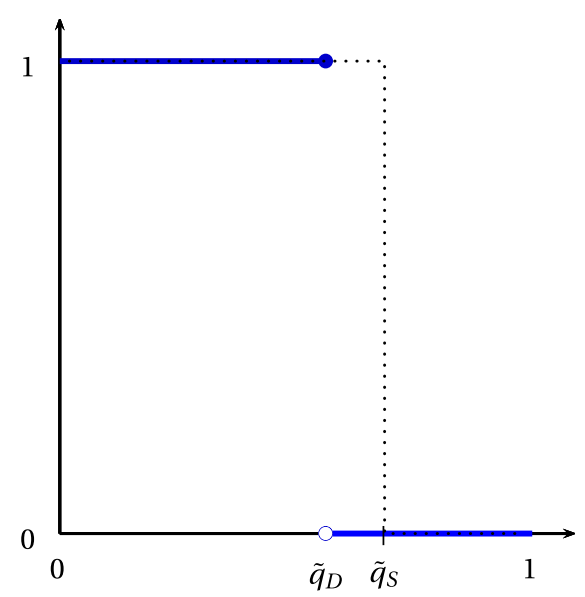

FIGURE 4. Equilibrium policy of electoral-competition game with mixed motives.

Proposition 6. In the case in which parties only care about office $\left(\psi^{N}=0\right)$ :

$$
\tilde{q}_{D}=\tilde{q}_{S} .
$$

On the contrary, if parties only care about nation-building, $(O=0)$ :

$$
\tilde{q}_{D}=0 .
$$

Note that when parties are purely office motivated, in every period they play the equilibrium strategy of the static game. ${ }^{24}$ Starting below the threshold $\tilde{q_{S}}$, pure electoral reasons push parties to implement full decentralization $\delta=1$, because this group is politically more powerful due to the combination of its demographic weight and the intensity of preferences of the group toward policy $\delta_{t}$. However, when both parties also have a nation-building motive, a region between $\tilde{q}_{D}$ and $\tilde{q}_{S}$ exists in which parties are not constrained to target announcements to the powerful regionalist group and have some margin to implement policies that favor nationalist voters (see Figure 4). The reason is that the nationalist group is big enough to guarantee a sufficiently large ex ante probability of winning the elections. In equilibrium, both parties announce $\delta=0$ and, due to the identity dynamics, the demographic weight $q_{t}$ increases endogenously over time until $\tilde{q}_{s}$ is reached and nation-building and electoral goals become aligned.

Finally, these results also suggest that, everything else equal, democracies tend to be more prone to accommodate and preserve regional identities than countries in which political power is not disputed. For example, consider the baseline model with $\psi^{U}=\psi^{S}=0$, so per-period utility of the central government is given by $W\left(q_{t}\right)=\psi^{n} q_{t}+1$, where the last term is the benefit of holding office obtained with certainty as no elections take place. Clearly, the optimal solution for the secure central government is to set $\delta(q)=0$ for all $q$, so nation-building will take place for any initial $q_{0} \in(0,1]$. By contrast,

\footnotetext{
${ }^{24}$ See the Supplementary Appendix S.5.2 for more details about our definition of a static political equilibrium.
} 
when the central government is elected democratically, a region always exists in which equilibrium strategies are given by full decentralization, $\delta=1$. Succinctly, the preservation of regional identities is more likely under electoral competition, because regional minorities have more voice in the political process. Moreover, the region where equilibrium strategies are $\delta^{i}=1$ is increasing in $\phi^{R}$, so democratic systems with powerful and ideologically motivated regional minorities are more likely to preserve their identities.

Finally, the following proposition characterizes how incentives to nation-build change with the parameters of the model.

Proposition 7. The threshold $\tilde{q}_{D}$ is decreasing in $\psi^{N}$ :

$$
\frac{\partial}{\partial \psi^{N}} \tilde{q}_{D} \leq 0
$$

with limiting cases

$$
\lim _{\psi^{N} \rightarrow 0} \tilde{q}_{D}=\tilde{q}_{S}, \quad \lim _{\psi^{N} \rightarrow \infty} \tilde{q}_{D}=0 .
$$

On the contrary, $\tilde{q}_{D}$ is increasing in $\rho$ :

$$
\frac{\partial}{\partial \rho} \tilde{q}_{D} \geq 0
$$

The proof can be found in Section S.5.5 of the Supplementary Appendix. It is easy to see that when the incentives to nation-build are larger, nation-building will occur for more initial states. Similarly, when parties are less patient, they are more concerned about short-run electoral goals and, therefore, nation-building will occur for fewer initial states. Moreover, as in the baseline model, small differences in the parameters or in the initial size of groups may have a large impact on the dynamics of identities.

\section{INTERPRETATION OF THE RESUlTS: CASE STUdies}

In this section, we discuss the main predictions of the model and we illustrate them with empirical evidence from historical case studies. The nonlinear and nonergodic nature of nation-building processes that our model stresses poses a challenge for standard empirical work and emphasizes the importance of studying nation-building episodes on a case-by-case basis. In addition, as Propositions 2, 3, 4, and 7 suggest, a myriad of different factors may tilt the balance for states about whether to implement nation-building policies. Moreover, how these sets of factors bundle together may differ across time and space. Hence, identifying the specific factors that played a role in different historical experiences may be more informative than looking for universal causes of nationbuilding. ${ }^{25}$

Despite the absence of a specific set of causes triggering nation-building episodes, our results highlight some important characteristics that they share. First, our model

\footnotetext{
${ }^{25}$ In fact, the vast literature in political science on this topic also suggests that general theories on the causes of nation-building and national identities are unhelpful for particular cases. See McCrone (1998) for further elaboration of this argument, and Wimmer and Feinstein (2010) for supportive empirical evidence.
} 
has multiple steady states, accounting for the diversity we observe across nations with respect to the spread of national sentiments in peripheral regions. Second, the steady state that is finally reached is very sensitive to initial conditions, because small initial differences could lead to opposite choices with a high degree of path dependency. This prediction fits a rich set of historical cases in which regions that were initially similar in terms of economic, political, and social factors have experienced completely divergent trajectories. ${ }^{26}$ Third, the model displays drastic regime changes: Sudden and extreme shifts in (de)centralization policies can be caused by exogenous shocks to the relative costs and benefits of nation-building, leading to opposite long-run outcomes. ${ }^{27}$ Fourth, nation-building episodes are relatively fast and extreme (MRAP behavior). Fifth, once sufficiently spread across the population, territorial identities are remarkably stable and difficult to reverse, because identities are reproduced over time inside the family (vertical socialization) and reinforced by the community (horizontal socialization). Sixth, regional identities are more likely to thrive in democracies than in dictatorships, because regionalists may be pivotal in reaching electoral majorities. Seventh, the model predicts a two-way causality between state centralization $(\delta)$ and the spread of the national identity $(1-q)$, because they tend to reinforce each other and to bundle together. Finally, although peripheral regions exists in which both identities have similar levels of attachment in the population, the model suggests that in the long run, one of the two identities will tend to become predominant.

Moreover, our theory highlights the fundamental role played of the state in purposefully shaping national identifications, which is in contrast to other explanations that emphasize a more bottom-up nature of this process and see national identifications as a byproduct of state modernization. ${ }^{28}$ Although these explanations are able to explain the rise of nationalism as an historical phenomenon and identify some necessary conditions for nation-building, they cannot explain why regional identities survived within countries that went through the process of modernization. ${ }^{29}$ Moreover, they cannot account for the divergence of outcomes for initially similar regions. In this sense, the two case studies discussed below provide support for the key role of top-down state socialization, because the crucial difference in both cases was the capacity and willingness of governments to promote national identities.

\footnotetext{
${ }^{26}$ In addition, this dependence on previous choices explains why short-sighted governments that do not internalize identity dynamics sometimes pursue cultural decentralization policies that become difficult to reverse.

${ }^{27}$ Nevertheless, changes in the parameters on the model or in the location of $q_{0}$ are not necessarily exogenous, because states may have additional instruments that affect them. For instance, Sambanis et al. (2015) note that some states, such as Prussia in the 19th century, engaged in international wars with the purpose of unifying the country by changing the value of $q_{0}$. Others have relied on internal migration to start the process of nation-building in peripheral regions (McGarry (1998)).

${ }^{28}$ The general idea underlying these theories is that the processes of urbanization and industrialization broke traditional parochial networks and spurred labor mobility. As a consequence, citizens from different backgrounds interacted with each other, which, in turn, promoted the emergence of a national identification. Moreover, this process of creating "imagined communities" was catalyzed by the advent of technologies permitting mass literacy in vernacular languages (Anderson (1991)).

${ }^{29}$ For instance, (Robinson (2014)) argues the strength of ethnic identifications intensified parallel with the process of modernization of African countries after decolonization.
} 
Case study I: Spanish versus French Catalonia Catalonia constitutes a paradigmatic case in which small differences in the initial conditions could amplify over time through the evolutionary process. At the beginning of the 17th century, Catalonia was an homogeneous region that was later split between France and Spain by the treaty of the Pyrenees in 1659. Since the split, Catalan national identity has persisted in both countries. However, this identity is prominent in today's Spanish political and social life, whereas it is almost negligible in France. ${ }^{30}$

According to McRoberts (2001), both parts of Catalonia remained relatively similar until the 18th century. In particular, Catalan regions on both sides of the border shared a common past, presented analogous degrees of linguistic and cultural homogeneity, and even kept some common legal institutions that were relatively independent from the central states. Despite these similarities, an obvious crucial difference was the ruling state and, in particular, the different set of incentives and constraints each state faced during the first decades of the 19th century. On the one hand, the Spanish state lacked the means to implement and enforce nation-building policies due to its inability to collect taxes (De Riquer (2001)). Moreover, its political power in relation to Catalan elites was relatively low, and the latter were able to mobilize the population around the idea of a Catalan identity (McRoberts (2001)). On the other hand, as Weber (1976) notes, during this time, the French state was characterized by a relatively strong state capacity. Therefore, it had the resources to implement mass schooling with a school curriculum designed to "make" French citizens. ${ }^{31}$ By contrast, as Enguita (2012) argues, universal schooling in Spain was not effective until the late 20th century, because the government did not have the financial means to provide schooling in rural areas. Moreover, the incentives for both states were relatively different. In particular, industrializing opportunities in France were greater at the beginning of the 19th century, increasing the benefits for the French central government of having an homogeneous population that could communicate in the same language (Gellner (1983)). In addition, the French state was involved in several external wars that needed an army of soldiers willing to fight for their nation (Aghion et al. (2019)). In our model, these initial differences correspond to slightly different levels of fiscal capacity $(r)$, damage created by regionalist political unrest $(1-\beta)$, and the nation-building motive parameter $\left(\psi^{N}\right)$, but not by substantive initial differences in $q_{0}$.

The Catalan case also highlights the high degree of path-dependency implied by the model. As Balcells (2013) shows, the failure of the Spanish state to spread the Spanish identity during the period of the "scholastic revolution" enabled the appearance of a regional revival movement (the "Renaixença") that promoted Catalan cultural values. As a

\footnotetext{
${ }^{30}$ For instance, according to Ethnologue, Catalan is the main language of communication for around $50 \%$ of the population in Spanish Catalonia, whereas this figure is 1\% in France.

${ }^{31}$ The case of French Catalonia also shows that successful nation-building episodes tend to be fast and characterized by homogenization policies that disregard regional particularities. As Weber (1976) notes, within a single generation, locally identified peasants became loyal "Frenchmen." This identification was achieved by what can be considered extreme (MRAP) interventions, such as the implementation of mandatory schooling and military services, the suppression of the use of the Catalan language in public administration, and the abolition of local institutions.
} 
result, more people were socialized to the Catalan identity. Therefore, when industrialization and state capacity levels in Spain resembled those in France a few decades earlier, instilling the national identity was no longer desirable for the Spanish government. In fact, the size of the regionalist group continued to grow and its political importance pushed the Spanish state to progressively grant more decentralization during the early 20th century.

Finally, the Catalan case exemplifies the difficulties in reverting formerly instilled territorial identities, as well as the importance of exogenous shocks in provoking drastic changes in nation-building policies. After the civil war (1936-1939), Franco's regime started a process of massive centralization, and implemented repressive and brutal measures aimed at eliminating the Catalan identity, in sharp contrast to the federal approach and policies of cultural recognition of the Second Spanish Republic (1931-1939). In terms of the model, the civil war and the posterior establishment of a fascist regime could be interpreted as a large shock that triggered a severe regime change in policies. In particular, it can be seen as a shock to the ability of Catalan regionalists to organize and protest, because during the civil war many of the Catalan leaders and citizens were killed, imprisoned, or forced into exile (a decrease in $(1-\beta)$ ). Also, the ideological shift of the new fascist regime, based on extreme Spanish nationalism, can be interpreted as a shock to $\psi^{N}$. However, Catalan identity was already widespread in society due to the weakness of the Spanish state during the 19th century (small $q_{0}$ ), and the measures implemented by Franco's regime did not significantly alter these previous identifications. In fact, with the advent of democracy 40 years later, the majority of Catalans were still attached to the regional identity. ${ }^{32}$ This new "shock" altered again the balance between the costs and benefits of promoting the national identity (because the success of the new democracy depended in part on the acceptance by the Catalan population), which triggered a radical switch in policies in favor of more federalism and the recognition of the cultural distinctiveness of the Catalan region. ${ }^{33}$

Case study II: Tanzania versus Kenya The case of Tanzania and Kenya is even more paradigmatic of the contingent nature of nation-building attempts and of the difficulties present in identifying a set of fundamental causes behind them. In a fascinating work, Miguel (2004) shows how the post-independence governments of Kenya and Tanzania, two countries that were similar in many respects, pursued radically different nationbuilding policies: Whereas the Tanzania government promoted Swahili as a national language, praised a national identity in schools, and dismantled tribal authorities, the Kenyan government allowed ethnic division. Over time, this difference in approaches created a national identity in Tanzania that is not present in Kenya.

The institutional and historical similarities between these two countries were remarkable, both in the colonial and early post-colonial period. Both countries have a

\footnotetext{
${ }^{32}$ Given the intergenerational nature of this process, possibly not enough time passed for nationbuilding policies to have a significant effect, especially given the low rate of change at early stages.

${ }^{33}$ This case also highlights one of the predictions of the electoral model in Section 6 regarding the possible different behavior of democracies and dictatorships. In particular, democracy gave Catalan regionalists the ability to influence the territorial and identity policies of the central government. In fact, Catalan parties have been pivotal in the national parliament several times during the democratic period.
} 
similar geography and population density, were former British colonies, became independent in the 1960's, and started afterwards from similar economic conditions. In the political realm, they both formed a one-party system and inherited similar administrative structures from the colonial period (Weber (2010)). Despite these similarities, (Barkan (1994)) claimed that the fundamental difference between the two countries lay in the fact that Tanzania had a large number of small ethnic groups, whereas Kenya was populated by fewer but larger ethnic groups with sufficient power to oppose the government's policies. Moreover, the concentration of capital was relatively higher in Kenya (Iliffe (1979)), which enabled some ethnic groups to arm themselves and fight violently the against the state, preventing nation-building. In our model, this explanation corresponds to a different initial value of $q_{0}$ and different value of $\beta$. Nevertheless, as Miguel (2004) notes, it seems that the crucial but small initial difference that led to divergent nation-building experiences were just "the personalities and philosophies of the respective independence leaders, Jomo Kenyatta and Julius Nyerere."

Moreover, the Tanzanian case nicely illustrates how nation-building policies are generally implemented in a fast and radical way, as implied by the MRAP solution of our model. As Miguel notes, "The Tanzanian regime quickly pushed for total Swahilization of government administration after independence and established the National Swahili Council to promote its use in all spheres of public life."

\section{CONCLUSION AND WAYS FORWARD}

In this paper, we develop a theoretical framework to illustrate the main mechanisms in nation-building processes, highlighting the importance of contingent historical circumstances in shaping the ability of states to nation-build. To conclude, we summarize the key results of the paper and outline a few potential extensions.

Our key theoretical contribution is to analyze the problem of a forward-looking leader who internalizes cultural dynamics and solves a zero-sum conflict between identity groups. This exercise yields three main results. First, the model displays multiple steady states and dependence on initial conditions, a typical characteristic of models with a logistic differential equation. Second, although the optimal trajectory of the control may vary with the choice of the objective function, all optimal paths eventually take extreme values for several specifications. That is, the government eventually provides only one type of public good, because providing both implies "investing" in opposite goals at the same time. Third, the optimal long run steady states are culturally homogeneous, even under cultural substitution between vertical and horizontal transmission channels, in contrast to previous results in the literature (e.g., Bisin and Verdier (2001); Verdier and Zenou (2018)). We have shown that two sufficient conditions must be satisfied for this long-run behavior. First, the cultural leader must be able to shape any nondegenerate identity distribution in any direction. Second, a strong enough conflict must exist over scarce resources between the two groups. Interestingly, the qualitative results are similar when we introduce dynamic electoral competition, and solve for the Markov Nash equilibrium of the differential game. 
One of the main limitations of the benchmark model is that total tax revenues are assumed to be exogeneously given and constant over time. To amend this shortcoming, in the Supplementary Appendix S.6, we explore the robustness of our results to the case of a government that also controls the tax rate. Interestingly, the ability of the government to soften the budget constraint does not change the qualitative results of the analysis. Because the zero-sum conflict between the two groups is still preserved for any positive tax rate, implementing policies that preserve both identities in the long run cannot be optimal.

The framework developed here can incorporate a number of important questions that may be addressed in future research. First, the model can be easily adapted to analyze the dynamic positive feedback between the fiscal capacity of states and the formation of national attachments (Johnson (2015)). In our model, a greater power to tax equips governments with more resources to forge stronger attachments to the nation. However, causality may also work in the other direction, because a shared national identity makes citizens more loyal to the state and facilitates tax collection by relying less on tax enforcement policies and more on quasi-voluntary compliance (Konrad and Qari (2012)). Therefore, endogenizing tax compliance in our model would help understand the role of nation-building policies as a state capacity investment. ${ }^{34}$

Second, in our model, nation-building policies operate by changing the (vertical) socialization incentives of parents. However, a vast literature in the social sciences and several recent papers in economics emphasize the essential role of the educational system in promoting national identities. ${ }^{35}$ Our framework can easily accommodate educational tools such as school curricula or mandatory schooling, by allowing the government to affect horizontal socialization directly.

Third, our analysis is based on the assumption of polarized and mutually exclusive identities. Although this type of identity cleavage has been the norm historically (Marx (2005)), in some regions, a number of individuals have "dual" or "mixed" identities, in the sense that they identify simultaneously with both regional and national cultural groups (Hierro and Gallego (2018), Stepan et al. (2011)). Introducing in our model a third group that derives utility from both types of public goods would allow the exploration of whether dual identities limit the scope of conflict that the government faces, which in turn may alter the full homogenization result. Solving the methodological difficulties present in this problem merits a separate paper and constitutes a very interesting extension.

Finally, in the paper, we analyzed the strategic interactions of two cultural leaders whose nation-building goals are aligned. However, we did not consider real-world examples in which central governments compete against local leaders that can encourage some identity resistance. Analyzing this possibility is an excellent topic for future research.

\footnotetext{
${ }^{34}$ See Besley and Persson (2011) for an extensive overview of questions related to state and fiscal capacity.

${ }^{35}$ See the related literature (Section 2 ) for some examples.
} 


\section{Appendix A: Mathematical appendix}

\section{A.1 Appendix for Section 4}

A.1.1 Proof of Proposition 1 The proof or Proposition 1 simply follows Spence and Starrett (1975). The main result is given by the following proposition.

Proposition 8. The government problem (1) is equivalent to a problem with flow utility given by a function $G\left(q_{t}\right)$; that is,

$$
\begin{gathered}
\max _{\delta_{t} \in[0,1] \forall t \geq 0} \int_{0}^{\infty} e^{-\rho t} W\left(\delta_{t}, q_{t}\right) d t \\
\text { s.t. } \dot{q}_{t}=r q_{t}\left(1-q_{t}\right)\left(1-\delta_{t}-q_{t}\right) \\
q(0)=q_{0}, q_{t} \in[0,1],
\end{gathered}
$$

is equivalent to problem

$$
\begin{gathered}
\max _{\delta_{t} \in[0,1] \forall t \geq 0} \int_{0}^{\infty} e^{-\rho t} G\left(q_{t}\right) d t \\
\text { s.t. } \dot{q}_{t}=r q_{t}\left(1-q_{t}\right)\left(1-\delta_{t}-q_{t}\right) \\
q(0)=q_{0}, q_{t} \in[0,1] .
\end{gathered}
$$

With the previous result, we prove Proposition 1.

Proposition 1. The optimal path for problem (1) is a most rapid approach (MRAP). That is, the optimal solution approaches as fast as possible a steady state in which perperiod welfare is maximized.

Proof. Given the linearity of $W\left(q_{t}, \delta_{t}\right)$ and $\dot{q}_{t}\left(q_{t}, \delta_{t}\right)$ in $\delta_{t}$, the only possible optimal policies are given by

$$
\delta_{t}^{*}=0 \quad \text { or } \quad \delta_{t}^{*}=1 \text {. }
$$

For sufficiency, observe that problem (1) can be equivalently rewritten as (5). Then the optimal solution is characterized by reaching a state that maximizes flow utility, $G(q)$, as fast as possible by setting $\delta_{t}^{*}=1$ or $\delta_{t}^{*}=0$ appropriately.

A.1.2 Shape of $G(q)$ From Proposition 1, we know that the optimal steady-states are characterized by the local maxima of $G(q)$, and thus those maxima need to be found. The following proposition shows where $G(q)$ is maximized.

Proposition 9. For any value of parameters, one has that

$$
\lim _{q \rightarrow 0} G(q)=\infty, \quad \lim _{q \rightarrow 1} G(q)=\infty,
$$

and a unique local minimum exists on the interval $(0,1)$. 
Proof. Observe that from the law of motion, we can express $\delta$ as a linear function of $\frac{\dot{q}}{r q(1-q)}$ and $q$,

$$
d(q, \dot{q})=1-q-\frac{\dot{q}}{r q(1-q)}=A_{1}+A_{2} q+A_{3} \frac{\dot{q}}{q(1-q)},
$$

with $A_{2} \leq 0$ and $A_{3} \leq 0$.

Substituting this expression inside the government's flow utility $W(q, \delta(q) ; \omega)$, we get

$$
W(q, \dot{q})=B_{0}+B_{1} q+B_{2} q^{2}+B_{3} \frac{\dot{q}}{(1-q)}+B_{4} \frac{\dot{q}}{q} .
$$

If we write $W(q, \dot{q})=M(q)+N(q) \dot{q}$, we can easily check that

$$
M(q)=B_{0}+B_{1} q+B_{2} q^{2}, \quad N(q)=B_{3} \frac{1}{(1-q)}+B_{4} \frac{1}{q},
$$

with $B_{3} \geq 0$ and $B_{4} \leq 0$ from $A_{3} \leq 0$ and the functional form of $W$. Hence, for $S(q)$, we have that

$$
S(q)=\int_{q_{0}}^{q} N(s) d s=\int_{q_{0}}^{q}\left(B_{3} \frac{1}{(1-s)}+B_{4} \frac{1}{s}\right) d s=C-B_{3} \ln (1-q)+B_{4} \ln (q),
$$

which is well-defined as long as $q_{0} \in(0,1)$.

Putting everything together

$$
G(q)=C_{0}+C_{1} q+C_{2} q^{2}+C_{3} \ln (1-q)+C_{4} \ln (q),
$$

with $C_{2} \geq 0$, because of the functional form of $W$ and $A_{2} \leq 0$, as well as $C_{3} \leq 0$, and $C_{4} \leq 0$. The first derivative of $G(q)$ is given by

$$
G^{\prime}(q)=C_{1}+2 C_{2} q-C_{3} \frac{1}{1-q}+C_{4} \frac{1}{q} .
$$

Moreover, the second derivative is always positive

$$
G^{\prime \prime}(q)=2 C_{2}-C_{3} \frac{1}{(1-q)^{2}}-C_{4} \frac{1}{q^{2}}>0,
$$

because $C_{2} \geq 0, C_{3}, C_{4} \leq 0$ for $q \in(0,1)$. Hence, $G(q)$ is strictly convex with a local minimum in $(0,1)$ and

$$
\lim _{q \rightarrow 0} G(q ; \omega)=\infty, \quad \lim _{q \rightarrow 1} G(q ; \omega)=\infty
$$

A.1.3 Proof of Theorem 1 According to Spence and Starrett (1975), the optimal trajectory of problem (1) consists of reaching as fast as possible the value of the state where $G(q)$ is locally maximized. In our case, $G(q)$ has no local maxima, so we cannot directly apply their approach. However, Theorem 1 modifies the results of Spence and Starrett (1975) that show that the solution to problem (1) is still characterized by an MRAP. 
Theorem 1. For any value of $\omega \in \Omega$ and any initial condition $q_{0} \in(0,1)$, optimal policies set either $\delta=0$ or $\delta=1$ forever with no switch in policies.

Furthermore, there is no interior steady state so optimal paths approach as fast as possible one of the extreme stationary points of the state variable:

$$
\lim _{t \rightarrow \infty} q_{t}^{*}=0 \quad \text { or } \quad \lim _{t \rightarrow \infty} q_{t}^{*}=1,
$$

where $q_{t}^{*}$ is the path of the state variable under the optimal policy $\delta^{*}$.

Proof. From Proposition 1, we know that any optimal policy will set $\delta_{t}^{*}=0$ or $\delta_{t}^{*}=1$. Assume initial conditions $q_{0}$. Recall the law of cultural transmission:

$$
\dot{q}_{t}=r q_{t}\left(1-q_{t}\right)\left(1-\delta_{t}-q_{t}\right) .
$$

Observe, from the law of motion, that the state variable $q_{t}$ will stay in $[0,1]$ for any choice of the control variable $\delta_{t}$. Moreover, it is easy to see from the previous equation that by setting $\delta_{t}$ appropriately, the government can reach any point $q \in(0,1)$ in finite time, and that it can also choose to stay at any given point $q_{t} \in(0,1)$ just by setting $\delta_{t}=1-q_{t}$ forever.

Now we prove the first part of the theorem. Observe that a swinging path covering any interval $I \subset[0,1]$ is not optimal. Clearly, a swinging path is dominated by staying at

$$
q^{*} \in \arg \max _{q \in I} G(q)
$$

Assume $w \log$ that $G\left(q_{0}\right) \geq \min _{q \in[0,1]} G(q)$ and that $q_{0} \geq \underset{q \in[0,1]}{\arg \min } G(q)$, as in Figure 5.

Now we prove the second part. Because continuity holds, we can only go either left or right with no jumps as shown by the arrows on the graph. Assume first that we go left. Any optimal path must reach $q_{1}$, because if not staying at $q_{0}$ forever strictly dominates that path, contradicting that the path is optimal.

Because of the first part of the proposition, we see that once we have reached $q_{1}$, a swinging path is not optimal on the interval $\left[q_{1}, q_{0}\right]$. In this case, any swinging path is clearly dominated by, for example, staying at $q_{0}$ the corresponding amount of time.

With a similar argument, we proceed to prove the second part of the theorem. Consider an arbitrary point $q_{2}$ to the left of $q_{1}$. The government is better off by reaching $q_{2}$ as fast as possible and staying there forever. Hence, we can rule out paths that never reach any $q_{2} \in\left(0, q_{1}\right]$. The case of going right under an optimal path starting from $q_{0}$ follows the same arguments.

A.1.4 Proof of Theorem 2 Theorem 1 shows that there are no interior steady states and that the long-run optimal is homogeneous. Theorem 2 characterizes the optimal policy and, therefore, how these steady-states are reached. 


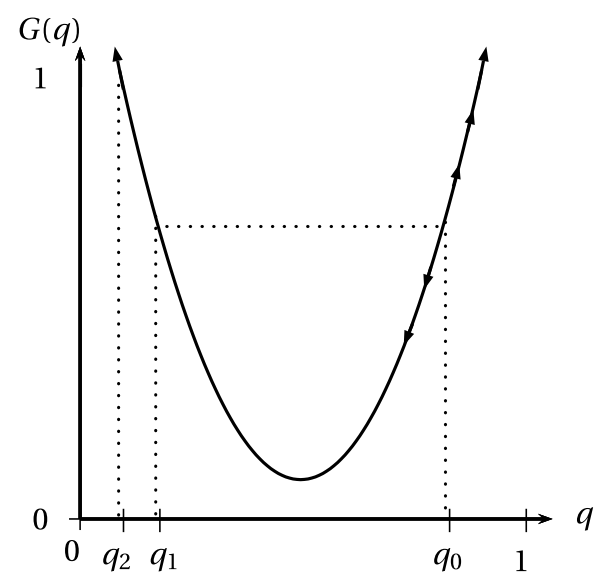

FIGURE 5. Optimal path on $G(q)$.

THеовем 2. For any parameter values, it exists a unique $\overline{q_{0}}$ such that the government is indifferent between setting $\delta^{*}=0$ or $\delta^{*}=1$ forever. That is, the optimal policy is characterized by threshold $\overline{q_{0}}$ as follows:

$$
\delta^{*}(q)= \begin{cases}1 & \text { if } q \leq \bar{q}_{0} \\ 0 & \text { if } q \geq \bar{q}_{0}\end{cases}
$$

Proof. Define

$$
F\left(q_{0}\right)=\int_{0}^{\infty} e^{-\rho t}\left[W\left(q_{t}^{1}\left(q_{0}\right), \delta=1\right)\right] d t-\int_{0}^{\infty} e^{-\rho t}\left[W\left(q_{t}^{0}\left(q_{0}\right), \delta=0\right)\right] d t
$$

s.t.

$$
\dot{q}^{\delta}=r q_{t}\left(1-q_{t}\right)\left(1-\delta_{t}-q_{t}\right), q(0)=q_{0} \quad \text { with } \delta \in\{0,1\},
$$

where $q^{\delta}$ is the path for $q$ when the government sets $\delta \in\{0,1\}$. Denote by $q^{\delta}\left(q_{0}\right)$ the solution to the differential equation $\dot{q}=q(1-q)(1-\delta-q)$ with initial condition $q_{0}$. That is

$$
\dot{q}^{0}=r q(1-q)^{2}, \quad \dot{q}^{1}=-r q^{2}(1-q) .
$$

Because setting $\delta=1$ or $\delta=0$ forever are the only possible optimal policies, $F$ represents the welfare difference between the only optimal policies at every initial point $q_{0}$. Therefore, when $F\left(q_{0}\right)>0$, it is optimal to set $\delta^{*}=1$ and, on the contrary, when $F\left(q_{0}\right)<0, \delta^{*}=0$ is optimal.

Evaluating $F\left(q_{0}\right)$ at $q_{0}=0$ and at $q_{0}=1$ yields:

$$
\begin{aligned}
& F(0)=\int_{0}^{\infty} e^{-\rho t} r(2-(\alpha+\beta)) d t=\frac{r}{\rho}(2-(\alpha+\beta))>0, \\
& F(1)=\int_{0}^{\infty} e^{-\rho t} r(-(\alpha+\beta)) d t=-\frac{r}{\rho}(\alpha+\beta)<0 .
\end{aligned}
$$




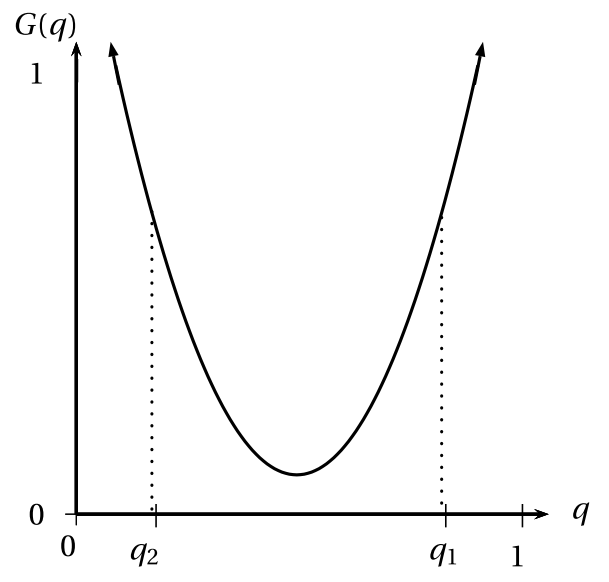

Figure 6. Uniqueness.

By continuity of $F\left(q_{0}\right)$ in $q_{0}$ and applying the intermediate value theorem, a $\overline{q_{0}}$ exists such that $F\left(\bar{q}_{0}\right)=0$. At that point, the government is indifferent between setting $\delta=0$ or $\delta=1$ for all $t \geq 0$.

It remains to show that the threshold $\overline{q_{0}}$ is unique. Assume two points exist for which we have indifference, say, $q_{1}$ and $q_{2}$ as depicted in Figure 6 . Without loss of generality, assume that $G\left(q_{1}\right) \geq G\left(q_{2}\right)$. Hence, at initial point $q_{1}$, the government can go to $q_{2}$ and then, because at $q_{2}$ it is indifferent between moving left or right, then government can go from $q_{2}$ to 0 . But observe that that path is dominated if we go directly from $q_{1}$ to 1 . Hence, going from $q_{1}$ to $q_{2}$ and then from $q_{2}$ to 0 cannot be optimal. Thus, $q_{1}$ and $q_{2}$ cannot be both indifference points.

\section{A.2 Appendix for Section 5}

First, let us denote by $V(q)$ the government discounted utility under the optimal policy

$$
\begin{aligned}
& V(q)=\max _{\delta_{t} \in[0,1]} \int_{0}^{\infty}-e^{-\rho t} W\left(q_{t}, \delta^{*}\left(q_{t}\right)\right) d t \\
& \text { s.t. } \dot{q}_{t}=r q_{t}\left(1-q_{t}\right)\left(1-\delta^{*}\left(q_{t}\right)-q_{t}\right) \text { and } q(0)=q,
\end{aligned}
$$

also known as the value function. Observe that the value function is well-defined and continuous on $[0,1]$ because

$$
\|W(q, \delta)\|<M<\infty
$$

for some $M<\infty$, and for all $q, \delta \in[0,1]$.

\section{A.2.1 Proof of Theorem 3}

Theorem 3. Assume that $\delta^{*}(q)$ is a solution to the following optimal control problem:

$$
\max _{\delta_{t} \in \Delta} \int_{0}^{\infty} e^{-\rho t} W\left(q_{t}, \delta_{t}\right) d t
$$




$$
\text { s.t. } \dot{q}_{t}=g\left(\delta_{t}, q_{t}\right) \text { and } q_{0}=q .
$$

Denote by $\delta^{S}(q)$ the stationary policy function

$$
\dot{q}=g\left(q, \delta^{S}(q)\right)=0,
$$

and define function

$$
H(q)=W\left(q, \delta^{S}(q)\right) .
$$

If for some interior $\tilde{q}$, we have that $\delta^{*}(\tilde{q})=\delta^{S}(\tilde{q}) \in \Delta^{\circ}$, such that $\{g(\tilde{q}, \delta) \mid \delta \in[0,1]\}$ is an open neighborhood of 0 , then $\tilde{q}$ is a local maximum of $H(q)$.

Proof. We prove it by contradiction. Assume that optimal policy is given by $\delta^{*}(q)$ and that for some $\tilde{q}$

$$
\delta^{*}(\tilde{q})=\delta^{S}(\tilde{q})
$$

such that $\{g(\tilde{q}, \delta) \mid \delta \in[0,1]\}$ is an open neighborhood of 0 so we can move in any direction at $\tilde{q}$, but $\tilde{q}$ is not a local maximum of $H(q)$. Without loss of generality, assume $H^{\prime}(\tilde{q})>0$. Pick any function $\epsilon(q)$ such that $\dot{\tilde{q}}=g\left(\tilde{q}, \delta^{S}(\tilde{q})+\epsilon(\tilde{q})\right)>0$ with policy $\delta^{S}(q)+\epsilon(q)$ feasible for an open neighborhood of $\tilde{q}$. Define $\bar{q}_{\tau}$ such that

$$
\bar{q}_{\tau}=q_{\tau},
$$

where $q$ follows the path defined by policy $\delta^{S}(q)+\epsilon(q) .{ }^{36}$ For every $\tau>0$, construct policy

$$
\delta_{\tau}^{\prime}(q)= \begin{cases}\delta^{S}(q) & \text { if } q=\bar{q}_{\tau}, \\ \delta^{S}(q)+\epsilon(q) & \text { if } q \neq \bar{q}_{\tau} .\end{cases}
$$

The intuition for policy $\delta_{\tau}^{\prime}$ is to move away from $\delta^{S}$ at an $\epsilon(q)$ rate until hitting $\bar{q}_{\tau}$, and stay at $\bar{q}_{\tau}$ forever afterwards. For example, if $\tau=0$, then $\delta^{\prime}(q)=\delta^{S}(q)$ for all $q$.

We want to compare $\delta^{*}$ with $\delta_{\tau}^{\prime}$ starting at $\tilde{q} \cdot{ }^{37}$ Given their definitions, the discounted utility for each policy is given by

$$
\begin{aligned}
& J\left(\tilde{q}, \delta^{*}\right)=\int_{0}^{\infty} e^{-\rho t} H(\tilde{q}) d t, \\
& J\left(\tilde{q}, \delta_{\tau}^{\prime}\right)=\int_{0}^{\tau} e^{-\rho t} W\left(q_{t}, \delta_{\tau}^{\prime}\left(q_{t}\right)\right) d t+e^{-\rho \tau}\left(H\left(q_{\tau}\right)\right) .
\end{aligned}
$$

Define $F(\tau)$ as the surplus difference between policy $\delta_{\tau}^{\prime}$ and $\delta^{*}$ :

$$
\begin{aligned}
F(\tau) & \equiv J\left(\tilde{q}, \delta_{\tau}^{\prime}\right)-J\left(\tilde{q}, \delta^{*}\right) \\
& =\int_{0}^{\tau} e^{-\rho t}\left(W\left(q_{t}, \delta_{\tau}^{\prime}\left(q_{t}\right)\right)-H(\tilde{q})\right) d t+e^{-\rho \tau}\left(H\left(q_{\tau}\right)-H(\tilde{q})\right) .
\end{aligned}
$$

\footnotetext{
${ }^{36}$ We omit the dependence on the initial value $q_{0}$ for the ease of exposition.

${ }^{37} \delta_{\tau}^{\prime}(q)$ might not be feasible for all $\tau$ and all initial values $q_{0}$, but since $\delta^{*}(\tilde{q})=\delta^{S}(\tilde{q}) \in \Delta^{o}, \delta_{\tau}^{\prime}(q)$ will be well-defined for sufficiently small $\tau$ in a neighborhood of $\tilde{q}$.
} 
Because $\delta^{*}$ is the optimal policy, it must be the case that $F(\tau) \leq 0$. However, observe that

$$
F(\tau)=F^{\prime}(0) \tau+o\left(\tau^{2}\right),
$$

because $F(0)=0$. Taking derivatives from (6) with respect to $\tau^{38}$

$$
F^{\prime}(\tau)=e^{-\rho \tau}\left(H\left(q_{\tau}\right)-H(\tilde{q})\right)-\rho e^{-\rho \tau}\left(W\left(q_{\tau}, \delta^{\prime}\left(q_{\tau}\right)\right)-H(\tilde{q})\right)+e^{-\rho \tau} H^{\prime}\left(q_{\tau}\right) \dot{q}_{\tau},
$$

and evaluating at $\tau=0$

$$
F^{\prime}(0)=H^{\prime}(\tilde{q}) \dot{\tilde{q}}>0,
$$

which contradicts the fact that $\delta^{*}$ is the optimal policy. ${ }^{39}$

A.2.2 Proof of Theorem 5 We proceed in steps. First, consider the corresponding HJB equation of problem (2):

$$
\begin{aligned}
\rho V(q)= & \max _{\delta \in[0,1]} \psi^{N} q+\alpha q(f(1-r)+r(1-\delta))+(1-\alpha)(1-q)((f(1-r)+r \delta) \\
& -r^{2}\left(\beta q \delta^{2}+(1-\beta)(1-q)(1-\delta)^{2}\right) \\
& +r q(1-q)(1-\delta-q) V^{\prime}(q) .
\end{aligned}
$$

Taking derivatives with respect to $\delta$, we obtain

$$
r((1-\alpha)(1-q)-\alpha q)-r^{2} 2(\beta q \delta-(1-\beta)(1-q)(1-\delta))-V^{\prime}(q) r q(1-q) .
$$

Hence, for an interior solution of $\delta^{*}(q)$, we can write

$$
\delta^{*}(q)=\frac{1}{\beta q+(1-\beta)(1-q)}\left((1-\beta)(1-q)+\frac{(1-\alpha)(1-q)-\alpha q-q(1-q) V^{\prime}(q)}{2 r}\right) .
$$

Because there is no interior steady state, it must hold that $\delta(q) \neq 1-q$ for all $q \in(0,1)$. This implies the following result.

Proposition 10. For any interior state $q \in(0,1)$, it follows that

$$
V^{\prime}(q) \neq s(q) \equiv 2 r(1-2 \beta)+\frac{1-\alpha}{q}-\frac{\alpha}{1-q} .
$$

Proof. We know that $\delta(q) \neq 1-q$ for all $q \in[0,1]$. Set $\delta=1-q$ in equation (7) and solve for $V^{\prime}(q)$.

\footnotetext{
${ }^{38}$ Recall that $\delta_{\tau}^{\prime}$ implicitly depends on $\tau$ and the term $\int_{0}^{\tau} \frac{\partial}{\partial \tau} \delta^{\prime}(q) e^{\rho t}\left(W\left(q_{t}, \delta^{\prime}\left(q_{t}\right)\right)-H(\tilde{q})\right) d t$ should be included in the derivative, too. However see the Supplementary Appendix S.4.1 to see that

$$
\int_{0}^{\tau} \frac{\partial}{\partial \tau} \delta^{\prime}(q) e^{\rho t}\left(W\left(q_{t}, \delta^{\prime}\left(q_{t}\right)\right)-H(\tilde{q})\right) d t=0 .
$$

${ }^{39}$ Even when $H^{\prime}(\tilde{q})=0$ the result still holds. If this is the case, we can use the second-order Taylor approximation of the function $F(\tau)$. For more details, see the Supplementary Appendix S.4.1.
} 
From the previous proposition, it follows that $V(q)$ is not differentiable at some $\bar{q} \in$ $(0,1)$, that is, $V(q)$ has a kink at some $\bar{q} \in(0,1)$. This result is shown in the following proposition.

Proposition 11. $V^{\prime}(q)$ is not continuous on $(0,1)$. Moreover, in a neighborhood of $q=1$ it must be the case that $V^{\prime}(q)>s(q)$ and, therefore, $\delta^{*}(q)<1-q$ and so $\dot{q}>0$. Similarly, in a neighborhood of $q=0, V^{\prime}(q)<1-q$, and $\delta^{*}(q)>1-q$ and so $\dot{q}<0$.

Proof. We know that

$$
V^{\prime}(q) \neq s(q)
$$

for all $q \in(0,1)$. The only way that $V^{\prime}(q)$ can be continuous is to have either $V^{\prime}(q)$ always above, or always below that function:

$$
V^{\prime}(q)>s(q) \text { or } \quad V^{\prime}(q)<s(q),
$$

for all $q \in(0,1)$. Without loss of generality, let us assume that $V^{\prime}(q)$ is continuous in $(0,1)$ with

$$
V^{\prime}(q)<s(q)=2 r(1-2 \beta)+\frac{1-\alpha}{q}-\frac{\alpha}{1-q} .
$$

This means that $V^{\prime}(q)<s(q)$ in a neighborhood of $q=1$. By continuity of $V^{\prime}(q)$ in $(0,1)$ it follows

$$
\lim _{q \rightarrow 1^{-}} V^{\prime}(q)=-\infty
$$

which contradicts the continuity of $V(q)$ at $q=1$. Therefore, it must the case that $V^{\prime}(q)>s(q)$ in a neighborhood of $q=1$. Following a similar argument, $V^{\prime}(q)<s(q)$ in a neighborhood of $q=0$. Hence, $V^{\prime}(q)$ is discontinuous at some $q \in(0,1)$.

Proposition 12. There is a threshold $\bar{q}_{0}$ such that

$$
V^{\prime}(q)>s(q) \quad \Longleftrightarrow \quad q>\bar{q}_{0} .
$$

Proof. We know from Proposition $11 \mathrm{a} q$ in $(0,1)$ exists at which $V^{\prime}(q)$ jumps function $s(q)$. We also know $V^{\prime}(q)<s(q)$ near $q=0$ as well as $V^{\prime}(q)>s(q)$ near $q=1$. Assume for a contradiction there is more than one jump. Then there is a point $\bar{q}_{1}$ such that for some $\epsilon>0, \dot{q}<0$ for all $q \in\left(\bar{q}_{1}, \bar{q}_{1}+\epsilon\right)$ and $\dot{q}>0$ for all $q \in\left(\bar{q}_{1}-\epsilon, \bar{q}_{1}\right)$ as shown in the example of Figure 7 . This would imply that $\bar{q}_{1}$ is an interior stationary point, which is a contradiction. ${ }^{40}$

Proposition 13. $\delta^{*}(q)=0$ in a open neighborhood of $q=1 . \delta^{*}(q)=1$ in an open neighborhood of $q=0$.

\footnotetext{
${ }^{40}$ Observe limit cycles are ruled out for dynamic autonomous systems or single variable with discount factor $\rho>0$, since the Jacobian of the canonical system, $J$, satisfies $\operatorname{tr}(J)=\rho>0$. For a more detailed discussion, see Grass et al. (2008), Proposition 3.83.
} 


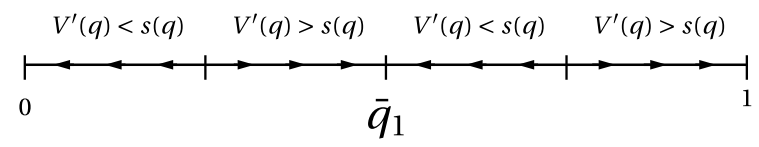

Figure 7. Example of many thresholds.

Proof. Assume for a contradiction that $\delta^{*}(q)>0$ near $q=1$. We know from Proposition 11 that $\delta^{*}(q)<1-q<1$ in some open neighborhood of $q=1$, say $\mathcal{O}(1)$. Therefore, for $q \in \mathcal{O}(1), \delta^{*}(q)$ is interior, $\delta^{*}(q) \in(0,1)$, and defined by the solution to the first-order condition

$$
\begin{aligned}
1 & >\delta^{*}(q)=\frac{1}{\beta q+(1-\beta)(1-q)}\left((1-\beta)(1-q)+\frac{(1-\alpha)(1-q)-\alpha q-q(1-q) V^{\prime}(q)}{2 r}\right) \\
& >0,
\end{aligned}
$$

which implies

$$
\frac{1-\alpha}{q}-\frac{\alpha}{1-q}+\frac{2 r(1-\beta)}{q}>V^{\prime}(q)>\frac{1-\alpha}{q}-\frac{\alpha}{1-q}-\frac{2 r \beta}{1-q} .
$$

By continuity of $V^{\prime}(q)$ in $\mathcal{O}(1) \cap(0,1)$ it must be the case that

$$
\lim _{q \rightarrow 1^{-}} V^{\prime}(q)=-\infty
$$

which contradicts again that $V(q)$ is continuous at $q=1$.

Proposition 14. The optimal policy $\delta^{*}(q)$ is continuous on $\left[0, \bar{q}_{0}\right) \cup\left(\bar{q}_{0}, 1\right]$.

Proof. It is easy to see that the optimal control satisfies

$$
\delta^{*}(0)=1 \delta^{*}(1)=0,
$$

which combined with continuity of $V^{\prime}(q)$ on $\left[0, \bar{q}_{0}\right) \cup\left(\bar{q}_{0}, 1\right]$ and Proposition 13 delivers the result.

COROLlaRY 7. The long-run steady state of $q_{t}$ are characterized as follows:

$$
\lim _{t \rightarrow \infty} q_{t}= \begin{cases}0 & \text { if } q_{0} \leq \bar{q}_{0}, \\ 1 & \text { if } q_{0} \geq \bar{q}_{0},\end{cases}
$$

with the property that $\bar{q}_{0}$ is a Skiba point of the dynamic system, that is, the government is indifferent between converging to $0, \lim _{t \rightarrow \infty} q_{t}=0$ or converging to $1, \lim _{t \rightarrow \infty} q_{t}=1$ at $\bar{q}_{0}$.

Proof. It follows directly from the the threshold characteristic of $\delta^{*}(q)$

$$
\delta^{*}(q)= \begin{cases}>1-q & \text { if } q_{0} \leq \bar{q}_{0}, \\ <1-q & \text { if } q_{0} \geq \bar{q}_{0} .\end{cases}
$$


Putting all the previous results together, we are able to prove Theorem 5:

Theorem 5. There exists $\bar{q}_{0} \in(0,1)$ such that

$$
\delta^{*}(q)>1-q \quad \text { if } q \leq \bar{q}_{0}, \quad \delta^{*}(q)<1-q \quad \text { if } q \geq \bar{q}_{0} .
$$

Moreover, $\delta^{*}(q)$ continuous on $\left[0, \bar{q}_{0}\right) \cup\left(\bar{q}_{0}, 1\right]$ and there two open neighborhoods of $q=0$ and $q=1$, say $\mathcal{O}(0)$ and $\mathcal{O}(1)$ in $[0,1]$, such that

$$
\delta^{*}(q)=1 \quad \forall q \in \mathcal{O}(0), \quad \delta^{*}(q)=0 \quad \forall q \in \mathcal{O}(1) .
$$

\section{A.3 Appendix for Section 6}

For details about the microfoundation of the objective function in the electoral competition game, see the Supplementary Appendix S.5. Observe that because $\left\|W\left(q, \delta^{i}, \delta^{-i}\right)\right\|=$ $\left\|\psi^{N} q+p_{i}\left(\delta^{i}, \delta^{-i}\right)\right\| \leq \psi^{N}+1<\infty$, we know that the value functions

$$
\begin{aligned}
V^{i}\left(q_{0}\right) & =\left\{\mathbb{E}_{0} \int_{0}^{\infty} e^{-\rho t} W^{i}\left(q_{t}, \delta^{* i}\left(q_{t}\right), \delta^{*-i}\left(q_{t}\right)\right) d t\right\}, \\
V^{-i}\left(q_{0}\right) & =\left\{\mathbb{E}_{0} \int_{0}^{\infty} e^{-\rho t} W^{-i}\left(q_{t}, \delta^{* i}\left(q_{t}\right), \delta^{*-i}\left(q_{t}\right)\right) d t\right\},
\end{aligned}
$$

are well-defined and continuous. The corresponding HJB equations are

$$
\begin{aligned}
\rho V^{i}(q) & =\max _{\delta \in[0,1]} W^{i}\left(q, \delta^{i}, \delta^{*-i}\right)+\mathbb{E}_{q}\left[g\left(q, \delta, \delta^{*-i}\right) V_{q}^{i}(q)\right], \\
\rho V^{-i}(q) & =\max _{\delta \in[0,1]} W^{i}\left(q, \delta^{i *}, \delta\right)+\mathbb{E}_{q}\left[g\left(q, \delta^{i *}, \delta\right) V_{q}^{-i}(q)\right],
\end{aligned}
$$

where $E_{q}$ is the expectation conditional on current state $q$. Given that two parties solve identical problems, we can restrict our attention to symmetric equilibria. Under symmetric equilibria, it follows that $V^{i}=V^{-i}=V$. Furthermore, it also holds

$$
\begin{aligned}
\mathbb{E}_{q} & {\left[g\left(q, \delta^{i}, \delta^{-i}\right) V_{q}(q)\right] } \\
\quad & =r q(1-q)\left(1-q-\left(p^{i}\left(\delta^{i}, \delta^{-i}\right) \delta_{i}+\left(1-p^{i}\left(\delta^{i}, \delta^{-i}\right)\right) \delta^{-i}\right)\right) V_{q}(q) .
\end{aligned}
$$

First, we prove some results that are used in the proof of Theorem 6.

Claim 1. Let $q^{0}(t)$ and $q^{h}(t)$ two paths defined by dynamics

$$
\dot{q}=r q(1-q)(1-q-\delta(q)),
$$

with initial conditions $q_{0}$ and $q_{0}+h$, respectively. Then

$$
q^{h}(t)>q^{0}(t) \quad \Longleftrightarrow \quad h>0, \quad \forall t \geq 0 .
$$


Proof. Observe both functions $q^{0}(t)$ and $q^{h}(t)$ are differentiable and, therefore, continuous. We prove the claim by contradiction. Suppose it does not hold. Because $q^{0}(t)$ and $q^{h}(t)$ are continuous with $q^{0}(0)=q_{0}<q^{h}(0)=q_{0}+h$, if the claim does not hold, a $\tilde{t}$ exists such that

$$
q^{0}(t)<q^{h}(t) \quad \forall t<\tilde{t} \quad \text { and } \quad q^{0}(\tilde{t})=q^{h}(\tilde{t})=\tilde{q} .
$$

The previous inequality implies

$$
\dot{q}^{0}(\tilde{t})=\lim _{\Delta \rightarrow 0} \frac{q^{0}(\tilde{t})-q^{0}(\tilde{t}-\Delta)}{\Delta}>\lim _{\Delta \rightarrow 0} \frac{q^{h}(\tilde{t})-q^{h}(\tilde{t}-\Delta)}{\Delta}=\dot{q}^{h}(\tilde{t}),
$$

which is a contradiction because at $\tilde{t}$ both dynamics are defined as

$$
\dot{q}^{0}(\tilde{t})=\dot{q}^{h}(\tilde{t})=\tilde{q}(1-\tilde{q})(1-\tilde{q}-\delta(\tilde{q})) .
$$

Using the previous claim, we have the following result.

Claim 2. At the points where $V(q)$ is differentiable, for any symmetric equilibrium of the nation-building electoral competition problem it must hold

$$
V_{q}(q) \geq 0 .
$$

Proof. Under any symmetric equilibrium, it follows

$$
p^{i}\left(q, \delta^{*}, \delta^{*}\right)=\frac{1}{2}
$$

Hence

$$
V(q)=\int_{0}^{\infty} e^{-\rho t}\left(\psi^{N} q_{t}+\frac{1}{2}\right) d t
$$

Therefore,

$$
V(q+h)-V(q)=\int_{0}^{\infty} e^{-\rho t}\left(q_{t}^{h}-q_{t}^{0}\right) d t>0,
$$

which implies $V_{q}(q) \geq 0$ for any symmetric equilibrium $\delta^{*}(q)$ because $q_{t}^{h}>q_{t}^{0}$ for any $h>0$.

Second, we show that equilibrium strategies cannot be interior, $\delta^{*}(q) \notin(0,1)$.

Proposition 15. For all $q \in[0,1]$, there is a unique symmetric equilibrium announcement that is not interior

$$
\delta^{*}(q) \in\{0,1\}
$$

Proof. We start by characterizing the best-response function $\delta^{* i}$ for given opponent's strategy $\delta^{-i}$ by solving the following problem:

$$
\rho V(q)=\max _{\delta \in[0,1]} \psi^{N} q+p^{i}\left(\delta, \delta^{-i}, q\right)+\mathbb{E}_{q}\left[g\left(q, \delta, \delta^{-i}\right) V_{q}(q)\right]
$$




$$
\begin{aligned}
= & \max _{\delta \in[0,1]} \psi^{N} q+\frac{1}{2}+\Phi(q)\left(\delta-\delta^{-i}\right) \\
& +r q(1-q)\left(1-q-\left[\frac{1}{2}\left(\delta+\delta^{-i}\right)+\Phi(q)\left(\delta-\delta^{-i}\right)^{2}\right]\right) V_{q}(q),
\end{aligned}
$$

where we have used $p^{i}\left(\delta, \delta^{-i}, q\right)=\frac{1}{2}+\Phi(q)\left(\delta-\delta^{-i}\right)$ with

$$
\Phi(q)=\frac{(1-q) \phi^{R}-q \phi^{N}}{q \phi^{N}+(1-q) \phi^{R}},
$$

and equation (8). We check for equilibrium strategies by invoking the one-shot deviation principle. Observe that in equation (9), tomorrow's payoff is included in the continuation value through the term $\mathbb{E}_{q}\left[g\left(q, \delta, \delta^{-i}\right) V_{q}(q)\right]$. That is, we check if the strategy of player $i$ is a best-response to $\delta^{-i}$ assuming that in the future players keep playing the equilibrium with associated payoff $V(q)$.

The first-order conditions of equation (9), which are given by

$$
\Phi(q)-r q(1-q) V_{q}(q)\left(\frac{1}{2}+2 \Phi(q)\left(\delta^{i}-\delta^{-i}\right)\right),
$$

with second-order conditions given by

$$
-r q(1-q) V_{q}(q) 2 \Phi(q) .
$$

We consider different cases, depending on the sign of $\Phi(q)$. Observe that the sign of $\Phi(q)$ determines the equilibrium announcement of a game without forward-looking parties that only care about winning the elections.

Case 1: $\Phi(q)<0$

When $q \in \Phi^{-} \equiv\{q \mid \Phi(q)<0\}$ and taking the other player strategy as given $\delta^{-i}$, the probability of winning the election for party $i$ is maximized at $\delta^{i}=0, \forall \delta^{-i}$. Since the continuation value $\mathbb{E}_{q}\left[g\left(q, \delta, \delta^{-i}\right) V_{q}(q)\right]$ is also maximized at $\delta^{i}=0$ given that $V_{q}(q) \geq 0$ for all $\delta^{-i}$, we have that $\delta^{i}(q)=0$ is a dominant strategy for $i=A, B$. Therefore, for $q \in \Phi^{-}$, there is a unique equilibrium with $\delta^{A}(q)=\delta^{B}(q)=0$.

Given the previous equilibrium announcements, we can solve for the value function in the subspace $\Phi^{-}$. Substituting equilibrium strategies inside the HJB equation, we obtain

$$
\rho V(q)=\psi^{N} q+\frac{1}{2}+r q(1-q)^{2} V_{q}(q) .
$$

When we substitute $H(q)=\rho V(q)-\left(\psi^{N} q+\frac{1}{2}\right)$, the resulting differential equation for $H(q)$ is given by

$$
H^{\prime}(q)-\frac{\rho}{r q(1-q)^{2}} H(q)=-\frac{\psi^{N}}{\rho} .
$$

We obtain the integrating factor of the previous ODE, $m(q)$, by solving $m_{q}(q)=$ $-\frac{\rho}{r q(1-q)^{2}} m(q)$. The solution is given by

$$
m(q)=C e^{-\frac{\rho}{r}\left(\ln (q)-\ln (1-q)+\frac{1}{1-q}\right)} .
$$


Hence, the solution to the original equation is

$$
m(1) H(1)-m(q) H(q)=-\int_{q}^{1} \frac{\psi^{N}}{\rho} m(q) d q .
$$

But since $m(1)=0$, the solution for $H(q)$ is

$$
H(q)=\frac{1}{m(q)} \int_{q}^{1} \frac{\psi^{N}}{\rho} m^{0}(q) d q,
$$

and so

$$
V(q)=\frac{\psi^{N} q}{\rho}+\frac{1}{2 \rho}+\frac{1}{m(q)} \int_{q}^{1} \frac{\psi^{N}}{\rho} m(q) d q,
$$

for all $q \in \Phi^{-}$.

Case 2: $\Phi(q)=0$

Observe that when $\Phi(q)=0$ it must be $q=\hat{q}_{S}$. In this case, the probability of winning is always $\frac{1}{2}$ and so it is independent of the announcements. Then, if $V_{q}\left(\hat{q}_{S}\right)>0$, then $\delta^{*}\left(\hat{q}_{S}\right)=0$ is also a dominant strategy and if $V_{q}\left(\hat{q}_{S}\right)=0$, then the whole interval $[0,1]$ is a dominant strategy.

It is easy to prove that we can only have $V_{q}\left(\hat{q}_{S}\right)>0$. Assume not, that is, $V_{q}\left(\hat{q}_{S}\right)=0$. Substituting $V_{q}\left(\hat{q}_{S}\right)=0$ in equation (9), it follows

$$
\rho V\left(\hat{q}_{S}\right)=\psi^{N} \hat{q}_{S}+\frac{1}{2} .
$$

By continuity of $V(q)$, it must hold

$$
\lim _{q \rightarrow \hat{q}_{S}^{+}} \rho V(q)=\rho V\left(\hat{q}_{S}\right) .
$$

Using the solution of the value function given in (10), we have

$$
\lim _{q \rightarrow \hat{q}_{S}^{+}} \rho V(q)=\psi^{N} \hat{q}_{S}+\frac{1}{2}+\frac{1}{m\left(\hat{q}_{S}\right)} \int_{\hat{q}_{S}}^{1} \frac{\psi^{N}}{\rho} m(q) d q,
$$

and so

$$
\frac{1}{m\left(\hat{q}_{S}\right)} \int_{\hat{q}_{S}}^{1} \frac{\psi^{N}}{\rho} m(q) d q=0 .
$$

This is a contradiction because $m(q)>0$ for all $q \in(0,1)$ with $m\left(\hat{q}_{S}\right)<\infty$ where $\hat{q}_{S}=$ $\frac{\phi^{N}}{\phi^{N}+\phi^{R}} \in(0,1)$.

Therefore, we conclude equilibrium announcements satisfy

$$
\delta^{*}(q)=0, \quad \forall \Phi(q) \leq 0 .
$$


Case 3: $\Phi(q)>0$

When $q \in \Phi^{+} \equiv\{q \mid \Phi(q)>0\}$, there is a trade-off between increasing the probability of winning elections and announcing a policy such that $q$ increases in the next period.

The best-response function to opponent's announcement $\delta^{-i}$ is characterized by the first-order conditions

$$
\Phi(q)-r q(1-q) V_{q}(q)\left(\frac{1}{2}+2 \Phi(q)\left(\delta^{i}-\delta^{-i}\right)\right),
$$

because the second-order conditions

$$
-r q(1-q) V_{q}(q) 2 \Phi(q) \leq 0
$$

given that $\Phi(q)>0$ and $V_{q}(q) \geq 0$. We proceed in cases:

- Case $V_{q}(q)=0$ : If $V_{q}(q)=0$, we are solving the static problem for which we know $\delta(q)=1$ is a dominant strategy. Therefore, if $V_{q}(q)=0$, the only equilibrium is $\delta^{*}(q)=1$.

- Case $_{q}(q)>0$ : We prove that there is no interior equilibrium by contradiction. Assume that for some $q \in \Phi^{+}$, there is such equilibrium with an interior announcement, say $\delta^{*}(q) \in(0,1)$. Because $V_{q}(q)>0$, the solution to the first-order conditions is a maximum. This solution, given opponent's strategy $\delta^{-i}$, is

$$
\delta^{i}=\delta^{-i}+\frac{1}{2 \Phi(q)}\left[\frac{\Phi(q)}{r q(1-q) V_{q}(q)}-\frac{1}{2}\right]=\delta^{-i}+\Theta(q),
$$

where $\Theta(q) \equiv \frac{1}{2 \Phi(q)}\left[\frac{\Phi(q)}{r q(1-q) V_{q}(q)}-\frac{1}{2}\right]$. Setting $\delta^{-i}$ equal to the best response of the player $-i$, we have that at an interior equilibrium announcement it must hold:

$$
\delta^{i}=\delta^{i}+2 \Theta(q) \Rightarrow \Theta(q)=0 \Rightarrow V_{q}(q)=\frac{2 \Phi(q)}{r q(1-q)} .
$$

If $\delta^{*}$ is an equilibrium announcement, it must also hold

$$
\begin{aligned}
\psi^{N} q & +\frac{1}{2}+r q(1-q)\left(1-q-\delta^{*}\right) V_{q}(q) \\
\geq & \psi^{N} q+\frac{1}{2}+\Phi(q)\left(\delta-\delta^{*}\right)+r q(1-q) \\
& \times\left(1-q-\left[\frac{1}{2}\left(\delta+\delta^{*}\right)+\Phi(q)\left(\delta-\delta^{*}\right)^{2}\right]\right) V_{q}(q),
\end{aligned}
$$

for all $\delta \in[0,1]$, which implies

$$
r q(1-q) V_{q}(q)\left(\frac{1}{2}+\Phi(q)\left(\delta-\delta^{*}\right)\right)\left(\delta-\delta^{*}\right) \geq \Phi(q)\left(\delta-\delta^{*}\right) .
$$

In particular, for $\delta \neq \delta^{*}$, we have that

$$
r q(1-q) V_{q}(q)\left(\frac{1}{2}+\Phi(q)\left(\delta-\delta^{*}\right)\right)=\Phi(q)+r q(1-q) V_{q}(q) \Phi(q)\left(\delta-\delta^{*}\right) \geq \Phi(q),
$$


where we have substituted $\frac{1}{2} r q(1-q) V_{q}(q)=\Phi(q)$. Simplifying the previous expression, it must hold

$$
r q(1-q) V_{q}(q) \Phi(q)\left(\delta-\delta^{*}\right) \geq 0,
$$

for all $\delta \in[0,1], \delta \neq \delta^{*}$. Given that $V_{q}(q)>0$ and $\Phi(q)>0$, which implies $q<1$, for $q>0$ the previous statement can only be true for all $\delta \in[0,1]$ if and only if $\delta^{*}=0$, which is not interior, a contradiction. For $q=0$, it is straightforward to see $\delta^{*}=1$ is the only equilibrium.

Hence because also $\delta^{*}(q) \notin(0,1)$ for any $q \in \Phi^{+}$, we finally conclude $\delta^{*}(q) \in\{0,1\}$ for all $q \in[0,1]$.

We are left to prove that for all $q \in[0,1]$ there is a unique symmetric equilibrium announcement. From the previous discussion, we already know the only equilibrium announcement for $q$ such that $\Phi(q) \leq 0$ is $\delta *(q)=0$. Let us look at $q$ such that $\Phi(q)>0$. If $V_{q}(q)=0$, it is straightforward to see that $\delta=1$ is a dominant strategy and, therefore, $\delta^{*}(q)=1$ is the unique equilibrium announcement. Now suppose that $V_{q}(q)>0$, so first-order conditions characterize a maximum and the best-response function is given by

$$
B R(\delta)= \begin{cases}1 & \text { if } \delta+\Theta(q)>1 \\ \delta+\Theta(q) & \text { if } \delta+\Theta(q) \in(0,1) \\ 0 & \text { if } \delta+\Theta(q)<0\end{cases}
$$

where $\Theta(q)=\frac{1}{2 \Phi(q)}\left[\frac{\Phi(q)}{r q(1-q) V_{q}(q)}-\frac{1}{2}\right]$.

Observe we can characterize equilibrium announcements by the fixed-point of the opponent's best response to a player's best response. In a symmetric equilibrium, the best-response functions of both players are identical, so equilibrium announcements are characterized as the fixed point of the best-response composition

$$
\delta=B R(B R(\delta))= \begin{cases}1 & \text { if } \delta+2 \Theta(q)>1, \\ \delta+2 \Theta(q) & \text { if } \delta+2 \Theta(q) \in(0,1), \\ 0 & \text { if } \delta+2 \Theta(q)<0 .\end{cases}
$$

It immediately follows:

- If $\Theta(q)>0$, the only fixed point of the best-response composition is $\delta=1$. In this case, the unique equilibrium is $\delta^{*}(q)=1$.

- If $\Theta(q)<0$, the only fixed point of the best-response function is $\delta=0$. In this case, the unique equilibrium is $\delta^{*}(q)=0$.

- If $\Theta(q)=0$, we use the previous discussion to show that there are no interior solutions and that the unique equilibrium announcement is $\delta^{*}(q)=0$.

With the following proposition, we show that the equilibrium policy is also characterized by a bang-bang as in the baseline model, with the property that the threshold of 
the dynamic electoral competition game, $\tilde{q}_{D}$ is always below the threshold of the static electoral competition game, $\tilde{q}_{S}$.

Proposition 16. A $q^{\prime}<\tilde{q}_{S}$ exists such that $\delta^{*}(q)=0$ is the equilibrium announcement for $q>q^{\prime}$.

Proof. Let us verify the announcement $\delta=0$ can be supported inside $\Phi^{+}$in a neighborhood around $\tilde{q}_{S}$ as an equilibrium. If that is the case, equation (9) must satisfy

$$
\rho V(q)=\psi^{N} q+\frac{1}{2}+r q(1-q)^{2} V_{q}(q) .
$$

Recall the solution of this differential equation is given by

$$
V(q)=\frac{\psi^{N} q}{\rho}+\frac{1}{2 \rho}+\frac{1}{m(q)} \int_{q}^{1} \frac{\psi^{N}}{\rho} m(q) d q,
$$

where $m(q)$ is the corresponding integrating factor.

From Proposition 15, we know that $\delta^{*}(q)=0$ can be supported as an equilibrium announcement if $\Theta(q)<0$, or equivalently $V_{q}(q)>\frac{2 \Phi(q)}{r q(1-q)}$ for $q \in \Phi^{+}$. We proceed to check this condition for the previous solution of the value function $V(q)$.

Taking derivatives with respect to $q$ from the previous expression, we obtain that

$$
V_{q}(q)=\psi^{N}\left[\frac{2}{\rho}+\frac{1}{r q(1-q)^{2} m(q)} \int_{q}^{1} m(x) d x\right]
$$

where we have used the fact that $m_{q}(q)=-\frac{\rho}{r q(1-q)^{2}} m(q)$. Observe that at $\tilde{q}_{S}$, the previous condition is satisfied for any $\psi^{N} \geq 0$ as

$$
\psi^{N}\left[\frac{2}{\rho}+\frac{1}{\tilde{q}_{S}\left(1-\tilde{q}_{S}\right)^{2} m\left(\tilde{q}_{S}\right)} \int_{\tilde{q}_{S}}^{1} m(x) d x\right]>\psi^{N} \frac{2}{\rho} \geq 0=2 \frac{2 \Phi\left(\tilde{q}_{S}\right)}{\tilde{q}_{S}\left(1-\tilde{q}_{S}\right)} .
$$

Moreover, if $\psi^{N}>0$ by continuity of $\frac{2 \Phi(q)}{q(1-q)}$ around $\tilde{q}_{S}$, this condition is satisfied in an open neighborhood of $\tilde{q}_{S}$, say $\mathcal{O}\left(\tilde{q}_{S}\right)$. That is, there exist $q^{\prime} \in \Phi^{+}$with $q^{\prime}<\tilde{q}_{S}$, such that $\delta^{*}(q)=0$ can be sustained as an equilibrium announcement for $q>q^{\prime}$.

This final proposition completes the characterization.

Proposition 17. $\delta^{*}(q)$ is decreasing, with at most one jump from 1 to 0 at some $\tilde{q}_{D}$. Moreover, $\delta^{*}\left(\tilde{q}_{D}\right)=1$.

Proof. Assume there is more than one jump, that is there is $\hat{q}$ such that we have a jump from 0 to 1 . It must be the case $\hat{q}<\tilde{q}_{S}$ because we know that $\delta^{*}(q)=0$ for all $q \geq \tilde{q}_{S}$, and so $\hat{q} \in \Phi^{+}$. By continuity of the value function, at any discontinuity of $\delta^{*}(q)$ it must hold

$$
\lim _{q \rightarrow \hat{q}^{-}} \psi^{N} q+\frac{1}{2}+q(1-q)^{2} V_{q}(q)=\lim _{q \rightarrow \hat{q}^{+}} \psi^{N} q+\frac{1}{2}-q^{2}(1-q) 2 V_{q}(q),
$$


which implies $V_{q}(\hat{q})=0$. In this case, for any discontinuity $q \in \Phi^{+}$, we know $\delta=1$ is a dominant strategy because $V_{q}(q=0$.

It also follows

$$
\lim _{q \rightarrow \hat{q}} q(1-q) V_{q}(q)=0 .
$$

But we can find an $\epsilon>0$ such that $\delta^{*}(q)=0$ for all with $(\hat{q}-\epsilon, \hat{q}) \subseteq \Phi^{+}$. Therefore, from Proposition 15 it must hold

$$
\Theta(q) \leq 0 \Longrightarrow 0<2 \Phi(q) \leq q(1-q) V_{q}(q),
$$

for $q \in(\hat{q}-\epsilon, \hat{q})$. Taking limits $q \rightarrow \hat{q}^{-}$,

$$
0 \leq 2 \Phi(\hat{q}) \leq \hat{q}(1-\hat{q}) V_{q}(\hat{q})=0,
$$

which implies $\Phi(\hat{q})=0$, and so $\hat{q}=\tilde{q}_{S}$, a contradiction. The last discussion proves that only one discontinuity of $\delta^{*}(q)$ exists, which we denote by $\tilde{q}_{D}$. Therefore, it must hold that $V_{q}\left(\tilde{q}_{D}\right)=0$.

Putting all results together we finally obtain obtain the result of Theorem 6 which shows that the equilibrium policy is also defined as a threshold policy.

THEOREM 6. There is a unique equilibrium in symmetric strategies of the dynamic electoral competition game with nation building motives. The equilibrium strategies are described as a threshold policy given by $\tilde{q}_{D}$ such that

$$
\delta^{A *}(q)=\delta^{B *}(q)= \begin{cases}1 & \text { if } q \leq \tilde{q}_{D} \\ 0 & \text { if } q>\tilde{q}_{D}\end{cases}
$$

with $0<\tilde{q}_{D}<\tilde{q}_{S}$, where $\tilde{q}_{S}$ defines the threshold of the symmetric equilibrium for the static electoral competition game, and is given by

$$
\tilde{q}_{S}=\frac{\phi^{R}}{\phi^{N}+\phi^{R}} .
$$

Proof. By Proposition 15, we know that either $\delta^{*}(q)=0$ or $\delta^{*}(q)=1$. We also know $\delta^{*}(0)=1$ and the function $\delta^{*}(q)$ is decreasing with only one discontinuity at some $\tilde{q}_{D}$, such that $\delta^{*}\left(\tilde{q}_{D}\right)=1$ from Proposition 17. Moreover, from Proposition 16, for any $\psi^{N}>$ 0 we know a $q<\tilde{q}_{S}$ exists such that $\delta^{*}(q)=0$. This implies that $\tilde{q}_{D}<\tilde{q}_{S}$. Then the equilibrium policy is given by

$$
\delta^{*}(q)= \begin{cases}1 & \text { if } q \leq \tilde{q}_{D} \\ 0 & \text { if } q>\tilde{q}_{D}\end{cases}
$$

The previous result delivers a very striking property of the optimal equilibrium path: Because no equilibrium announcement is interior, the only long-run steady states are $q=0$ or $q=1$. 
Proposition 18. The long-run steady states of the nation-building electoralcompetition game are located at 0 and 1 .

Proof. Equilibrium announcements are never interior. Therefore, for every $q \in(0,1)$, $\delta^{*}(q) \neq 1-q \Rightarrow \dot{q} \neq 0$. Therefore, no interior steady state exists under equilibrium strategies.

\section{A.3.1 Proof of Proposition 6}

Proposition 6. In the case that parties only care about office, $\psi^{N}=0$, it holds

$$
\tilde{q}_{D}=\tilde{q}_{S}
$$

On the contrary, if parties only care about nation-building, $O=0$, it holds

$$
\tilde{q}_{D}=0
$$

Proof. First, we find the symmetric equilibrium for the special cases $\psi^{N}=0$ and $O=0$. Consider first that there is no nation-building motive, that is $\psi^{N}=0$. In every period, both parties compete to split a pie of size 1 and, therefore, the sum of payoffs is constant for every period. It immediately follows that the sum of discounted payoffs is also constant and, therefore, the previous game is a constant-sum game for any starting point $q \in[0,1]$. As in any constant-sum game, all equilibria are payoff-equivalent, with payoff $V(q)=\frac{1}{2 \rho}$ for all $q$. Therefore, continuation values are independent of future $q$ and equilibrium strategies must maximize the per-period probability of winning elections. More concretely, because all equilibrium payoffs are given by $V(q)=\frac{1}{2 \rho}$ for all $q \in[0,1]$, then $V_{q}(q)=0$ and the HJB equation of the dynamic problem collapses to the problem of the static game. Then the equilibrium strategies are given by

$$
\delta^{i *}(q)=\arg \max _{\delta^{i}} p^{i}\left(\delta^{i}, \delta_{-i}, q\right)= \begin{cases}1 & \text { if } \Phi(q)>0, \\ {[0,1]} & \text { if } \Phi(q)=0, \\ 0 & \text { if } \Phi(q)<0,\end{cases}
$$

which is independent of $\delta^{*-i}(q)$. Moreover, because $\frac{\partial \Phi(q)}{\partial q}<0$ and dynamics satisfy $\dot{q}_{t}>$ 0 if $\delta=1, \dot{q}_{t}<0$ if $\delta=1$, we have that on equilibrium $\Phi^{-}$and $\Phi^{+}$are invariant sets, meaning that under equilibrium strategies

$$
q_{t} \in \Phi^{-} \Longleftrightarrow q_{0} \in \Phi^{-}, \forall t \geq 0
$$

Therefore, for given initial $q_{0}$, the equilibrium path for $\left\{\delta_{t}^{*}\right\}_{t \geq 0}$ is fully defined by

$$
\delta_{t}^{*}= \begin{cases}1 & \text { if } q_{0}<\tilde{q}_{S} \\ {[0,1]} & \text { if } q_{0}=\tilde{q}_{S}, \\ 0 & \text { if } q_{0}>\tilde{q}_{S}\end{cases}
$$




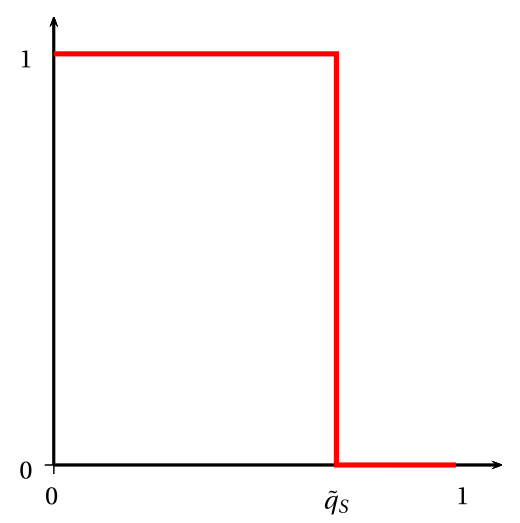

FIgURE 8. Equilibrium of static game.

which is exactly the same solution as in the static electoral competition game (see Figure 8). Moreover, as in the baseline model with a secure government, the long-run steady states are located at $q=0$ and $q=1$, and which one occurs is only determined by the initial $q_{0}$.

Consider now the other limiting case, when political parties are not office motivated, that is, $W^{i}\left(q, \delta^{i}, \delta^{-i}\right)=\psi^{N} q$. In this game, it can be easily checked with the HJB equations that the unique Markov-perfect equilibrium is $\delta^{A}(q)=\delta^{B}(q)=0, \forall q$, and $\forall t \geq 0$. Intuitively, parties have aligned nation-building incentives and do not care about winning elections per se. Given that both derive benefits from increasing $q$, it is optimal for them to do it in the fastest way.

\section{REFERENCES}

Achdou, Yves, Jiequn Han, Jean-Michel Lasry, Pierre-Louis Lions, and Benjamin Moll (2017), Income and Wealth Distribution in Macroeconomics: A Continuous-Time Approach. Working paper, NBER Working Paper No. 23732. [777]

Aghion, Philippe, Xavier Jaravel, Torsten Persson, and Dorothée Rouzet (2019), "Education and military rivalry." Journal of the European Economic Association, 17, 376-412. $[767,784]$

Alesina, Alberto and Bryony Reich (2015), "Nation building." Working paper, NBER WP 18839. [767]

Alesina, Alberto, Bryony Reich, and Alessandro Riboni (2017), Nation-Building, Nationalism and Wars. Working paper, NBER Working Paper No. 234. [767]

Anderson, Benedict (1991), Imagined Communities: Reflections on the Origin and Spread of Nationalism. Verso, New York, New York. [783]

Aspachs-Bracons, Oriol, Irma Clots-Figueras, Joan Costa-Font, and Paolo Masella (2008), "Compulsory language educational policies and identity formation." Journal of the European Economic Association, 6, 434-444. [767] 
Bakke, Kristin M. and Erik Wibbels (2006), "Diversity, disparity, and civil conflict in federal states.” World Politics, 59, 1-50. [764]

Balcells, Laia (2013), “Mass schooling and Catalan nationalism." Nationalism and Ethnic Politics, 19, 467-486. [784]

Bandiera, Oriana, Myra Mohnen, Imran Rasul, and Martina Viarengo (2019), "Nationbuilding through compulsory schooling during the age of mass migration." Economic Journal, 129, 62-109. [767]

Barkan, Joel D. (1994), Beyond Capitalism versus Socialism in Kenya and Tanzania. East African Publishers, Nairobi. [786]

Besley, Timothy and Torsten Persson (2011), Pillars of Prosperity: The Political Economics of Development Clusters. Princeton University Press. [787]

Besley, Timothy and Marta Reynal-Querol (2014), "The legacy of historical conflict: Evidence from Africa.” American Political Science Review, 108, 319-336. [764]

Bisin, Alberto and Thierry Verdier (2000), "A model of cultural transmission, voting and political ideology." European Journal of Political Economy, 16, 5-29. [768]

Bisin, Alberto and Thierry Verdier (2001), "The economics of cultural transmission and the dynamics of preferences.” Journal of Economic Theory, 97, 298-319. [765, 769, 786]

Bisin, Alberto and Thierry Verider (2011), "The economics of cultural transmission and socialization." In Handbook of Social Economics, volume 1A (Jess Benhabib, Matthew O. Jackson, and Alberto Bisin, eds.), 339-416, North-Holland, San Diego. [766]

Blouin, Arthur and Sharun W. Mukand (2019), "Erasing ethnicity? Propaganda, nation building, and identity in Rwanda.” Journal of Political Economy, 127, 1008-1062. [767]

Breton, Albert (1964), “The economics of nationalism.” Journal of Political Economy, 72, 376-376. [767]

Caminal, Ramon, Lorenzo Cappellari, and Antonio Di Paolo (2018), Linguistic Skills and the Intergenerational Transmission of Language. Working paper, IZA Discussion Paper No. 11793, SSRN 3249907. [767]

Cantoni, Davide, Yuyu Chen, David Y. Yang, Noam Yuchtman, and Y. Jane Zhang (2017), “Curriculum and ideology." Journal of Political Economy, 125, 338-392. [767]

Carvalho, Jean-Paul and Mark Koyama (2016), "Jewish emancipation and schism: Economic development and religious change.” Journal of Comparative Economics, 44, 562584. [767]

De Riquer, Borja (2001), Escolta, Espanya: la cuestión catalana en la época liberal. Marcial Pons Historia, Madrid, Spain. [784]

Depetris-Chauvin, Emilio, Ruben Durante, and Filipe R. Campante (2018), "Building nations through shared experiences: Evidence from African football." Working paper, NBER Working Paper No. 24666. [767] 
Dessí, Roberta (2008), "Collective memory, cultural transmission, and investments." American Economic Review, 98, 534-560. [767]

Enguita, Mariano Fernández (2012), "Building the nation at school: Spain's tables turned: Mariano Fernández Enguita." In The Politics of Education: Challenging Multiculturalism, 74-95, Routledge, New York, New York. [784]

Fouka, Vasiliki (2020), "Backlash: The unintended effects of language prohibition in US schools after World War I.” Review of Economic Studies, 87, 204-239. [767]

Gellner, Ernest (1983), Nations and Nationalism. Cornell University Press, Ithaca, New York. [784]

Gennaioli, Nicola and Guido Tabellini (2018), "Identity, beliefs, and political conflict." Unpublished paper, Bocconi University, Department of Economics, SSRN 3300726. [768]

Grass, Dieter, Jonathan P. Caulkins, Gustav Feichtinger, Gernot Tragler, and Doris A. Behrens (2008), "Optimal control of nonlinear processes." Springer-Verlag. [795]

Guiso, Luigi, Helios Herrera, and Massimo Morelli (2016), "Cultural differences and institutional integration.” Journal of International Economics, 99, S97-S113. [764]

Guiso, Luigi, Paola Sapienza, and Luigi Zingales (2016), “Monnet's error?” Economic Policy, 31, 247-297. [764]

Hauk, Esther and Giovanni Immordino (2014), "Parents, television and cultural change.” Economic Journal, 124, 1040-1065. [767]

Hierro, María José and Aina Gallego (2018), "Identities in between: Political conflict and ethnonational identities in multicultural states." Journal of Conflict Resolution, 62, 13141339. [787]

Iliffe, John (1979), A Modern History of Tanganyika. Cambridge University Press, New York, New York. [786]

Johnson, Noel D. (2015), “Taxes, national identity, and nation building: Evidence from France." Unpublished paper, George Mason University, Department of Economics, SSRN 2593331. [770, 787]

Konrad, Kai A. and Salmai Qari (2012), "The last refuge of a scoundrel? Patriotism and tax compliance.” Economica, 79, 516-533. [787]

Lindbeck, Assar and Jörgen W. Weibull (1987), "Balanced-budget redistribution as the outcome of political competition.” Public Choice, 52, 273-297. [779]

Madestam, Andreas and David Yanagizawa-Drott (2012), Shaping of the Nation: The Effect of Fourth of July on Political Preferences and Behavior in the United States. Working Paper, HKS Faculty Research Working Paper, Series RWP12-034, John F. Kennedy School of Government, Harvard University. [767]

Marx, Anthony W. (2005), Faith in Nation: Exclusionary Origins of Nationalism. Oxford University Press, New York, New York. [787] 
McCrone, David (1998), The Sociology of Nationalism: Tomorrow's Ancestors. Routledge, New York, New York. [782]

McGarry, John (1998), “'Demographic engineering': The state-directed movement of ethnic groups as a technique of conflict regulation." Ethnic and Racial Studies, 21, 613638. [783]

McRoberts, Kenneth (2001), Catalonia: Nation Building Without a State. Oxford University Press, Ontario, Canada. [784]

Miguel, Edward (2004), "Tribe or nation? Nation building and public goods in Kenya versus Tanzania." World politics, 56, 327-362. [785, 786]

Passarelli, Francesco and Guido Tabellini (2017), “Emotions and political unrest.” Journal of Political Economy, 125, 903-946. [771]

Persson, Torsten. and Guido Tabellini (2000), Political Economics: Explaining Economic Policy. MIT Press, Cambridge, Massachusetts. [779]

Prummer, Anja and Jan-Peter Siedlarek (2017), "Community leaders and the preservation of cultural traits.” Journal of Economic Theory, 168, 143-176. [767]

Robinson, Amanda Lea (2014), "National versus ethnic identification in Africa: Modernization, colonial legacy, and the origins of territorial nationalism." World Politics, 66, 709-746. [783]

Sambanis, Nicholas and Moses Shayo (2013), "Social identification and ethnic conflict." American Political Science Review, 107, 294-325. [767]

Sambanis, Nicholas, Stergios Skaperdas, and William C. Wohlforth (2015), "Nationbuilding through war." American Political Science Review, 109, 279-296. [767, 783]

Sekulic, Dusko, Garth Massey, and Randy Hodson (1994), "Who were the yugoslavs? Failed sources of a common identity in the former Yugoslavia." American Sociological Review, 59, 83-97. [764]

Shayo, Moses (2009), "A model of social identity with an application to political economy: Nation, class, and redistribution.” American Political Science Review, 103, 147-174. $[767,768]$

Smith, Anthony D. (1992), "National identity and the idea of European unity." International affairs, 68, 55-76. [766]

Spence, Michael and David Starrett (1975), "Most rapid approach paths in accumulation problems.” International Economic Review, 16, 388-403. [765, 772, 788, 789]

Spolaore, Enrico (2013), "What is European integration really about? A political guide for economists.” Journal of Economic Perspectives, 27, 125-144. [764]

Stepan, Alfred, Juan J. Linz, and Yogendra Yadav (2011), Crafting State-Nations: India and Other Multinational Democracies. Johns Hopkins University Press, Baltimore, Maryland. [787] 
Tabellini, Guido (2008), “The scope of cooperation: Values and incentives.” Quarterly Journal of Economics, 123, 905-950. [768]

Verdier, Thierry and Yves Zenou (2018), "Cultural leader and the dynamics of assimilation.” Journal of Economic Theory, 175, 374-414. [768, 786]

Voigtländer, Nico and Hans-Joachim Voth (2015), "Nazi indoctrination and anti-semitic beliefs in Germany." Proceedings of the National Academy of Sciences, 112, 7931-7936. [767]

Weber, Anke (2010), "The causes of politicization of ethnicity-a comparative case study of Kenya and Tanzania." Unpublished paper, APSA 2010 Annual Meeting Paper, SSRN 1643450. [786]

Weber, Eugen (1976), Peasants Into Frenchmen: The Modernization of Rural France, 1870-1914. Stanford University Press, Stanford, California. [764, 784]

Wimmer, Andreas and Yuval Feinstein (2010), "The rise of the nation-state across the World, 1816 to 2001." American Sociological Review, 75, 764-790. [782]

Co-editor Dilip Mookherjee handled this manuscript.

Manuscript received 19 October, 2017; final version accepted 25 September, 2019; available online 25 October, 2019. 